\title{
The Gender Earnings Gap in the Gig Economy: Evidence from over a Million Rideshare Drivers *
}

\author{
Cody Cook, Rebecca Diamond, Jonathan Hall \\ John A. List, and Paul Oyer
}

JANUARY 2018

\begin{abstract}
The growth of the "gig" economy generates worker flexibility that, some have speculated, will favor women. We explore one facet of the gig economy by examining labor supply choices and earnings among more than a million rideshare drivers on Uber in the U.S. Perhaps most surprisingly, we find that there is a roughly $7 \%$ gender earnings gap amongst drivers. The uniqueness of our data - knowing exactly the production and compensation functions - permits us to completely unpack the underlying determinants of the gender earnings gap. We find that the entire gender gap is caused by three factors: experience on the platform (learning-by-doing), preferences over where/when to work, and preferences for driving speed. This suggests that, as the gig economy grows and brings more flexibility in employment, women's relatively high opportunity cost of non-paid-work time and gender-based preference differences can perpetuate a gender earnings gap even in the absence of discrimination.
\end{abstract}

* We thank seminar participants for valuable input.

Cook and Hall: Uber Technologies, Inc.; Diamond and Oyer: Stanford University Graduate School of Business and NBER; List: University of Chicago, NBER, and Uber Technologies, Inc. 


\section{Introduction}

"The converging roles of men and women are among the grandest advances in society and the economy in the last century. But what must the last chapter contain for there to be equality in the labor market?

It must involve changes in the labor market, especially how jobs are structured and remunerated to enhance temporal flexibility. The gender gap in pay would be considerably reduced and might vanish altogether if firms did not have an incentive to disproportionately reward individuals who labored long hours and worked particular hours. " Goldin (2014)

The wage gap between men and women has narrowed throughout the past four decades, with 2010 estimates suggesting women earn 88 cents on the dollar as compared to similar men in similar jobs (Blau and Kahn (2017)). ${ }^{1}$ Much of the remaining wage gap can be explained by fewer hours worked and weaker continuity of labor force participation by women, especially for middle-age workers where gender wage gaps are largest (Bertrand et al. (2010), Goldin and Katz (2016), Blau and Kahn (2017)). Goldin (2014) has suggested that work hours and disruption in labor force participation dramatically lower wages due to a "job-flexibility penalty," where imperfect substitution between workers can lead to a convex hours-earnings relationship. In contrast, the role of on-the-job training (Mincer and Polachek (1974)) is thought to play an economically smaller role (Blau and Kahn $(2017)) .^{2}$

Recently, many experts have taken an interest in the "gig" economy, which can be loosely defined as a collection of labor markets that divide work into small pieces and then offer those pieces of work to independent workers in real-time with low barriers to entry. Although measuring the economic importance of the gig economy is difficult, estimates suggest about $15 \%$ of U.S. workers primarily do independent work, that $30 \%$ do some independent work, and that the share is growing (Katz and Krueger (2016), Oyer (2016), and McKinsey Global Institute (2016)). Female workers may be particularly drawn to gig work because of its flexible hours and transparent compensation. ${ }^{3}$

\footnotetext{
${ }^{1}$ See Table 4 Panel B of Blau and Kahn (2017), combining the residual wage gap with the effects of experience.

${ }^{2}$ Blau and Kahn (2017) note that the evidence here is mostly based on older studies (Light and Ureta (1995)). Indeed, data on experience often contain sizable measurement error in traditional datasets (Blau and Kahn (2013)).

${ }^{3}$ Hyperwallet (2017) reports that " $86 \%$ of female gig workers believe gig work offers the opportunity to make equal pay to their male counterparts."
} 
In this paper, we make use of a sample of over a million drivers to quantify the determinants of the gender earnings gap in one of the largest gig economy platforms: Uber's platform for connecting riders and drivers. Uber set its driver fares and fees through a simple, publicly available formula, which is invariant between drivers. Further, similar to many parts of the larger gig economy, on Uber there is no negotiation of earnings, earnings are not directly tied to tenure or hours worked per week, and we can demonstrate that customer-side discrimination is not materially important. These job attributes explicitly rule out the possibility of a "job-flexibility penalty." ${ }^{4}$ We use granular data on drivers and their behaviors in a given hour of the week to precisely measure driver productivity and returns to experience.

We find that men earn roughly $7 \%$ more per hour than women on average, which is in line with prior estimates of gender earnings gaps within specifically defined jobs (Bayard et al. (2003), Barth et al. (2017)). We can explain the entire gap with three factors. First, through the logic of compensating differentials, hourly earnings on Uber vary predictably by location and time of week, and men tend to drive in more lucrative locations. The second factor is work experience. Even in the relatively simple production of a passenger's ride, past experience is valuable for drivers. A driver with more than 2,500 lifetime trips completed earns $14 \%$ more per hour than a driver who has completed fewer than 100 trips in her time on the platform, in part because she learn where to drive, when to drive, and how to strategically cancel and accept trips. Male drivers accumulate more experience than women by driving more each week and being less likely to stop driving with Uber. Because of these returns to experience and because the typical male Uber driver has more experience than the typical female-putting them higher on the learning curve-men earn more money per hour.

The residual gender earnings gap that persists after controlling for these two factors can be explained by a single variable: average driving speed. Increasing speed increases expected driver earnings in almost all Uber settings. Drivers are paid according to the distance and time they travel on trip and, in the vast majority of cases, the loss of per-minute pay when driving quickly is

\footnotetext{
${ }^{4}$ This is in contrast with taxi markets in cities such as New York with supply-limiting medallions. In these markets, because the cost of switching drivers is that a valuable medallion will be off the road, contracts are generally structured to make it uneconomical for taxi drivers not to work a very long day. See Haggag et al. (2017).
} 
outweighed by the value of completing a trip quickly to start the next trip sooner and accumulate more per-mile pay (across all trips). We show that men's higher driving speed is due to taste as drivers appear insensitive to the incentive to drive faster. Men's higher average speed and the productive value of speed for Uber and the drivers (and, presumably, the passengers) enlarges the pay gap in this labor market.

We interpret these determinants of the gender pay gap-more experience, different locations, and higher speed - as taste-based characteristics that are correlated with gender and make drivers more productive. While much prior work has also shown a relationship between the gap and factors that are likely to be related to tastes, we know of no prior work that fully decomposes the gender earnings gap in any setting. Beyond measuring the gender earnings gap and unpacking it completely in an important labor market, our simple analysis provides insights into the roots of the gender earnings gap and, following the approach described in Gelbach (2016), the share of the pay gap that can be explained by each factor. First, driving speed alone can explain nearly half of the gender pay gap. Second, over a third of the gap can be explained by returns to experience, a factor which is often almost impossible to evaluate in other contexts that lack high frequency data on pay, labor supply, and output. The remaining $\sim 20 \%$ of the gender pay gap can be explained by choices over where to drive. Men's willingness to supply more hours per week (enabling them to learn more) and to target the most profitable locations shows that women continue to pay a cost for working reduced hours each week, even with no convexity in the hours-earning schedule. As the gig economy continues to grow, it will likely bring even more flexibility in earnings opportunities, which is valued by at least some workers (Angrist et al. (2017) and Chen et al. (2017)) document the value of flexibility to drivers) if not by all workers (see Mas and Pallais (2017)). However, the returns to experience and the temporal and geographic variation in worker productivity will likely persist and thus lead to a persistent gender earnings gap.

The remainder of the study proceeds as follows. We begin with a select summary of the literature studying gender pay gaps. We then describe our data, and show that, using data from well over a million drivers on Uber, there is a roughly $7 \%$ gap in hourly earnings between men and women. Having established that there is a gender earnings gap for drivers, we study the details 
of how drivers are compensated so that we can break down all components that affect driver pay. We focus on drivers in the Chicago metropolitan area to reveal the primary determinants of the earnings gap. ${ }^{5}$ We conclude with implications and summary remarks.

\section{Literature}

For a general overview of the literature on male/female wage differentials and the factors that lead to them, see Altonji and Blank (1999), Bertrand (2011), and Blau and Kahn (2017). While there are many papers that compare men's and women's earnings across broad groups of the population, a more limited set of papers takes the approach taken here of looking at gender differences within a single company and/or a narrowly defined set of workers.

Bayard et al. (2003) uses employer-employee matched data in the US from 1989 to analyze within-establishment gender pay gaps. They find a gender pay gap of $16 \%$ within occupations and establishments, which can account for about $50 \%$ of the overall pay gap. Since these results are almost three decades old and the economy-wide gender gap has narrowed substantially in the intervening years (Blau and Kahn (2017)), this suggests our Uber gender gap of $7 \%$ is likely not far from the typical within-firm gap.

Several prior papers have shown clear empirical connections between gender pay gaps and factors that are likely related to gender differences in preferences. For example, Bertrand et al. (2010) focus on how pay differences are related to intensity of work. Looking at graduates of a single prestigious MBA program, they show that there is a relatively small gender pay gap (about 4\%) at graduation which widens considerably with post-MBA experience. The initial gap is driven by women being far less likely to take jobs in finance (which could be due to taste differences or discrimination). The authors show that the increase in the gap can be explained almost entirely by differences in hours worked, due to a combination of women working fewer hours per week (conditional on working) and being more likely to have gaps in their careers. There is a (statistically insignificant) unexplained pay gap of $4 \%$ after they control for hours worked (at the time of the observation and over an entire career), industry, MBA grades and classes, and all other available observables. Most of the gender

\footnotetext{
${ }^{5}$ We have replicated our empirical work in other metropolitan areas and the conclusions are invariably the same.
} 
gap is explained by hours worked, which is rooted in differences related to child rearing. ${ }^{6}$ The mechanism for the hours/earnings connection is unclear as the authors cannot determine whether the female earnings penalty is due to a convex hours-earnings relationship or a learning-by-doing effect. Our results (though in a very different context) are surprisingly similar and our data enable us to quantify the importance of learning-by-doing.

Goldin and Katz (2016) show that hours worked differences play out very differently in the market for pharmacists. Pharmacists have become increasingly female over time, and the gender pay gap amongst pharmacists is a small $4 \%$. This $4 \%$ is completely driven by women who have children; they find no gender gap within those without children. As compared to the MBAs in Bertrand et al. (2010), the importance of hours and child rearing is economically weaker, although still statistically significant. The institutional setting of pharmacists employment suggest little scope for a "job-flexibility penalty," although empirically it is challenging to distinguish this effect from on-the-job learning and returns to experience without more detailed data.

Azmat and Ferrer (2017) study the gender gap in the market for young lawyers in the United States. They document a large earnings premium for men. Controlling for performance measures such as hours billed and new clients brought in, the gender pay gap becomes statically insignificant (though they cannot reject a gender gap of at least 6\%). Gallen (2015) draws similar conclusions from a broad sample of Danish workers, finding that mothers are much less productive than other women or men, which explains most of the wage difference they face. Consistent with our conclusions for drivers on Uber and those of Bertrand et al. (2010) for MBA's, these papers highlight the importance of gender differences in preferences as driving the gender gap.

Card et al. (2015) relate pay to another gender preference difference - difference in the willingness to bargain. Using matched employee/employer data from Portugal, Card et al. (2015) show that the gender pay gap is exacerbated by proxies for firm-level rents - that is, the gap increases when the firm has a high firm-specific pay premium. They also show a dramatic level of sorting by gender into different firms and that the combination of sorting and firm-specific pay levels ac-

\footnotetext{
${ }^{6}$ Similar conclusions can be drawn from the analysis in Barth et al. (2017). They look at the gender gap over careers and by education. They show that the gender gap grows substantially with age for the college-educated due to men's pay rising faster within establishments.
} 
counts for $80 \%$ of the gender pay gap. They attribute the lower female return to firm-specific pay premia to women bargaining less aggressively. Black and Strahan (2001) show that the gender pay gap declined (and the fraction of women increased) when U.S. banks were deregulated, which they interpret as competitive pressures reducing the banks' surplus available to share with favored (male) employees. Both papers (as well as related results in Hirsch et al. (2010)) show that a large share of the gender pay gap can be attributed to some combination of bargaining and employer discrimination, though it is difficult to clearly distinguish between these channels (as evidenced by the different interpretations of the authors of the two papers).

In addition to Card et al. (2015), other papers look at how the gender pay gap may be related to yet another difference in preferences: different tastes leading to differential sorting into jobs. For example, Gupta and Rothstein (2005) use matched employer/employee data to show that Danish men earned about 34\% more per hour than Danish women in 1995. A full set of controls for human capital observables and establishment-by-occupation indicator variables allows them to explain almost $60 \%$ of the gap leaving a $14 \%$ hourly residual. This pay gap suggests that a large part of gender pay differences can be explained by differential sorting into firms and occupations. However, a large share remains unexplained and the sorting could be (at least partially) driven by discrimination, in hiring or elsewhere. Bayard et al. (2003) reach similar conclusions using U.S. data.

A related area of research includes studies that explore the gender pay gap using experimental techniques. This work varies from examining how gender is related to preferences for incentive schemes in the lab (see, e.g., Gneezy et al. (2003)) and in the field (Flory et al. (2015)), to measuring gender preferences for bargaining and negotiations (see, e.g., Babcock and Laschever (2003), Leibbrandt and List (2015)). The typical data pattern observed is that women disproportionately shy away from competitive work settings, and that men are more likely to negotiate than women. Scholars have used these findings as potential explanations for the portion of the gender pay gap attributed to unobservables in the studies that examine naturally-occurring data. 


\section{Uber: Background and Data}

\subsection{The Uber Marketplace}

Uber's software connects riders with drivers willing to provide trips at posted prices. Riders can request a trip through a phone app, and this request is then sent to a nearby driver. The driver can either accept or decline the request during a short time window after seeing the rider's location. If the driver declines the ride, then the request is sent to another nearby driver. Some products slightly vary this experience. For example, UberPOOL trips may involve picking up multiple riders traveling along a similar route. At the end of each ride, the passenger and driver rate each other on a scale from one to five stars.

Drivers have full discretion regarding when and where they work. Unlike wage and salary workers, drivers do not receive standard employee benefits like overtime or healthcare. A comprehensive discussion of the classification of drivers as independent contractors is out of the scope of this paper, but driver independence is convenient for this study insofar as we do not need to consider differential value for different kinds of compensation beyond monetary compensation and flexibility.

Drivers are paid according to a fixed, non-negotiated formula. For a given trip, the driver earns a base fare plus per-minute and per-distance rates for the time and distance from pickup to dropoff. In times of imbalanced supply and demand, as manifested by high wait times and few available drivers, a "surge" multiplier greater than one may multiply the time and distance-based fare formula. Importantly, there are no explicit returns to tenure (e.g., promotion), convex returns to hours worked (i.e. higher pay for the 50th hour of work in a week than the 20th), or opportunities for earnings discrepancies based on negotiated pay differentials on Uber. ${ }^{7}$

In our analysis, we will essentially be treating earnings as equivalent to productivity. This is a reasonable assumption on any single trip, as driver earnings for a trip are highly correlated with rider fares. $^{8}$

\footnotetext{
${ }^{7}$ Occasionally, certain promotions will pay for convex hours worked by rewarding drivers for hitting certain thresholds of weekly trips. However, incentives are a small portion of the average driver's pay and our results also hold when considering only "organic" pay.

${ }^{8}$ Before Summer 2016, driver pay and rider fares for a trip were directly coupled, with a percentage service fee taken by Uber. However, rider fares are now 'decoupled' and, while correlated with driver earnings, are not mechanically tied to earnings. Furthermore, while Uber now allows riders to tip their drivers in-app, this did not become available
} 
One concern is that, if a driver takes an action that increases or decreases a rider's demand for future Uber rides, then a trip's revenue could overstate or understate the driver's marginal product of labor for that ride. For our analysis, this is only an issue if there are differences by driver gender in how drivers affect future demand. To address this, we looked at the ratings passengers provide for drivers at the end of each ride. Reassuringly for our approach, the average of rider ratings of drivers is statistically indistinguishable between genders. When we regress ratings on gender and the control variables used throughout the paper, we find an economically trivial (and, in most specifications, statistically insignificant) relationship between driver gender and ratings. These analyses provide some reassurance that there are not important differences by driver gender in drivers' effects on Uber's reputation or a rider's propensity to take future Uber rides.

In our analysis, we focus on the UberX and UberPOOL products to ensure that drivers in our data were completing comparable work and faced similar barriers to entry; other Uber products may have alternative pay structures (e.g., UberEATS) or stricter car and license requirements (e.g., UberBLACK).

\subsection{Driver Earnings}

For each trip completed, drivers are paid a base fare plus a per-mile and per-minute rate. In Chicago (as of 2017), drivers are paid a $\$ 1.70$ base fare plus $\$ 0.20$ per minute and $\$ 0.95$ per mile for each UberX trip (which are all, at times of high demand, multiplied by a surge multiplier). ${ }^{9}$

Drivers can also earn money from "incentives." For example, drivers may be offered additional pay for completing a set number of trips in a week. Another type of incentive guarantees drivers a certain surge level for trips taken within a given geography and time (e.g. 1.4x all fares in the Chicago Loop during rush hour). While the use of incentives has varied over time, on average they account for under $9 \%$ of a driver's hourly earnings in our data.

until June 2017, which is outside the scope of our data. We do not believe that cash tips - which were possible before in-app tipping - had a material impact on driver earnings.

${ }^{9}$ For UberX trips, there is also a minimum fare of $\$ 4.60$ in Chicago. 
With all of these components in mind, we formalize the driver's effective hourly earnings $p(\cdot)$ for a given trip as

$$
p(\cdot)=60 *\left(\frac{S M\left(r_{b}+d_{1} r_{d}+60 * \frac{d_{1} r_{t}}{s}\right)+I}{w+60 * \frac{d_{0}+d_{1}}{s}}\right)
$$

where $r_{b}, r_{d}$, and $r_{t}$ respectively represent the base fare, per-mile, and per-minute rates, $S M$ is the surge multiplier, $d_{0}$ is the distance between accepts and pickup, $d_{1}$ is the distance on trip, $s$ is speed, $w$ is wait time for dispatch, and $I$ represents the incentive earnings associated with the trip.

For UberPOOL trips - where multiple riders heading in the same direction can ride togetherthe pay formula treats the chain of trips as a single trip. The driver still receives a base fare for the initial pickup plus a per-mile and per-minute rate. ${ }^{10}$ Importantly, pay does not depend on the number of riders in the car. We return to this construction of driver earnings below and isolate how variation in each parameter of Equation 3.1 contributes to gender pay differences for drivers.

\subsection{National data}

Our national data include all driver-weeks for drivers in the U.S. from January 2015 to March 2017. We limit the data to drivers for Uber's "peer-to-peer services," UberX and UberPOOL; drivers who have completed a trip on other products such as UberXL, UberBLACK, or UberEATS are excluded. ${ }^{11}$ The resulting data include 1,877,252 drivers, 513,417 of whom are female (27.3\%). ${ }^{12}$ In total, we observe 24.9 million driver-weeks in 196 cities. $^{13}$

For each driver-week, we track total earnings and hours worked. We compute hourly earnings as the total payout in that week divided by hours worked. For the purposes of this paper, a driver is considered to be "working" whenever the app is on and available for trips; that is, while on a trip, enroute to a pickup, or available for a dispatch. All earnings are gross earnings. Costs such as gas,

\footnotetext{
${ }^{10}$ UberPOOL rates are sometimes marginally lower than UberX rates. In Chicago, the per-mile and base fare are identical to UberX, but the per-minute rate is 6 cents lower.

${ }^{11}$ UberEats has a different pay structure than ride sharing, paying piece-rate for pickups, dropoffs, and miles driven, and has less stringent vehicle requirements for drivers. Results are consistent with or without UberEats drivers. UberBLACK drivers are commercially licensed and may face large regulatory barriers to entry depending on the city.

${ }^{12}$ This percentage is higher than the number of active women drivers in a given month due to women having higher attrition (Table 1).

${ }^{13}$ We follow Uber's definition of city, which does not always match canonical definitions. For example, the state of New Hampshire is considered a single city.
} 
car depreciation, and Uber's service fee have not been subtracted from the earnings we present. ${ }^{14}$

We discuss costs in more depth in the appendix.

\subsection{Summary Statistics}

Table 1 presents summary statistics of driver pay overall by gender. Active drivers gross an average of $\$ 375$ per week and $\$ 21$ per hour. More than $60 \%$ of those who start driving are no longer active on the platform six months later (though some of these drivers may be on an extended break). Comparing across gender in Table 1, we find a first hint of differences between male and female drivers. Men make nearly 50\% more per week than women, which is primarily a reflection of their choice to work nearly $50 \%$ more hours per week. On an hourly basis, men make over $\$ 1 /$ hour more. ${ }^{15}$ Men are also less likely to leave the platform; as we will discuss further below, this factor strongly contributes to the hourly earnings gap.

Table 1: Basic summary statistics, all US drivers

\begin{tabular}{lccc}
\hline & All & Men & Women \\
\hline Weekly earnings & $\$ 376.38$ & $\$ 397.68$ & $\$ 268.18$ \\
Hourly earnings & $\$ 21.07$ & $\$ 21.28$ & $\$ 20.04$ \\
Hours per week & 17.06 & 17.98 & 12.82 \\
Trips per week & 29.83 & 31.52 & 21.83 \\
6 month attrition rate & $66.6 \%$ & $63.3 \%$ & $75.9 \%$ \\
Number of drivers & $1,873,474$ & $1,361,289$ & 512,185 \\
Number driver/weeks & $24,832,168$ & $20,210,399$ & $4,621,760$ \\
Number of Uber trips & $740,627,707$ & $646,965,269$ & $93,662,438$ \\
\hline
\end{tabular}

Note: Values are based on all UberX/UberPOOL driver-weeks in the US from January 2015 - March 2017. The percent of drivers who are female varies across city; to mitigate composition effects, we weight averages at the city level by total number of drivers in a city, rather than by number of male (or female) drivers. 6 month attrition rate is the percent of drivers who are no longer active 6 months after the month they completed their first trip.

\footnotetext{
${ }^{14}$ Uber increased its service fee from $20 \%$ to $25 \%$ in Sept 2015; however, drivers who joined before then were grandfathered in and still pay only $20 \%$. This differentially impacts women, who are more likely to have joined the platform more recently. We look at earnings before the service fee is applied.

${ }^{15}$ An informal survey by The Rideshare Guy, a blog covering ridesharing, found a gender pay gap of over $\$ 2$ per hour; however, in addition to being self-reported earnings, this does not control for gender composition effects across cities (The Rideshare Guy (2017)).
} 
Figure 1 provides a graphical view of the hourly earnings gap for all U.S. drivers from early 2015 through early 2017. The gap seen in Table 1 is fairly constant throughout the sample period. Pay of drivers fluctuates, but the changes are generally gender neutral.

Figure 1: Average hourly earnings, US

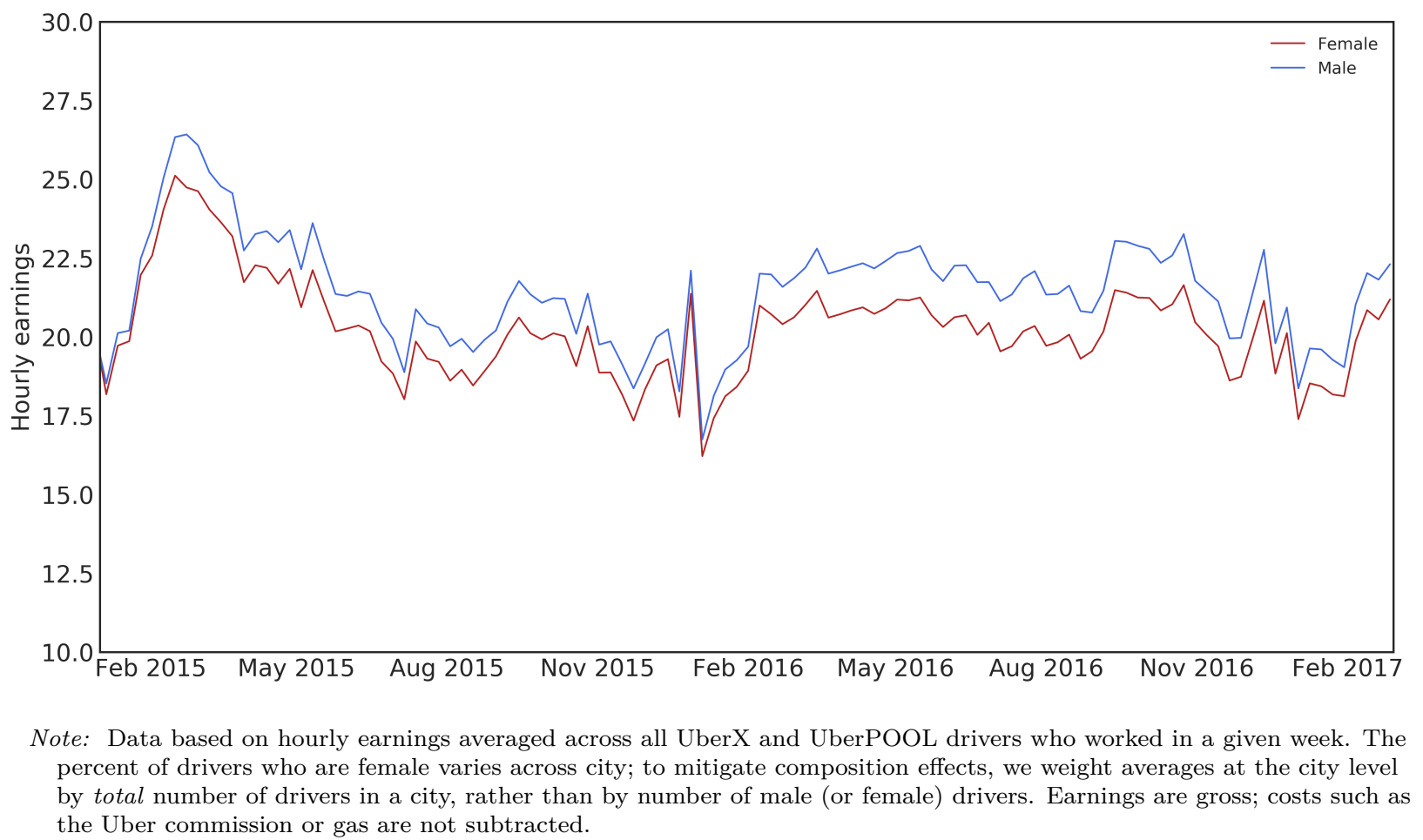

Table 2 uses these national data and measures the Uber driver gender pay gap through a set of standard Mincer regressions. Specifically, we estimate

$$
\ln \left(\text { Earnings }_{d t}\right)=\beta_{0}+\beta_{1} \text { is }_{\text {Male }}+\rho X_{d t}+\epsilon_{d}
$$

for driver $d$ in time period $t$, where Earnings are the gross weekly or hourly earnings in that time period, as described above, isMale is an indicator variable for a driver's gender, and $X_{d t}$ is a set of controls such as week and city indicator variables.

Table 2 provides clear evidence that, when examining almost two million drivers (representing more than one percent of the United States workforce) across the entire country and controlling for the city and the conditions for a given week, there remains a large gender pay gap. Men earn 
Table 2: National gender pay gap

\begin{tabular}{lcccc}
\hline & $(1)$ & $(2)$ & $(3)$ & $(4)$ \\
& $\log ($ weekly earnings $)$ & $\log ($ weekly earnings $)$ & $\log ($ hourly earnings $)$ & $\log$ (hourly earnings) \\
\hline isMale & 0.4142 & 0.4092 & 0.0702 & 0.0653 \\
& $(0.002)$ & $(0.002)$ & $(0.001)$ & $(0.001)$ \\
Intercept & 4.9737 & 4.9208 & 2.9280 & 2.8849 \\
& $(0.002)$ & $(0.002)$ & $(0.001)$ & $(0.001)$ \\
City & $\mathrm{X}$ & $\mathrm{X}$ & $\mathrm{X}$ & $\mathrm{X}$ \\
Week & & $\mathrm{X}$ & $24,877,588$ & $\mathrm{X}$ \\
\hline $\mathrm{N}$ & $24,877,588$ & $24,877,588$ & $1,877,252$ & $24,877,588$ \\
Drivers & $1,877,252$ & $1,877,252$ & 0.199 & $0.877,252$ \\
$R^{2}$ & 0.125 & 0.136 & 0.239 \\
\hline
\end{tabular}

Note: This table documents the gender pay gap for all US cities from January 2015 to March 2017. Data are at the driverweek level; weekly earnings is the entire pay for a given week, while hourly earnings is the pay divided by hours worked in the week. Standard errors (clustered at the driver-level) in parentheses.

about $7 \%$ more than women when the analysis is done at the hourly level, indicating that, while a substantial majority of the weekly earnings gender gap is simply due to men driving more hours, there is still a substantial gap when looking at hourly earnings.

This gap may seem surprising: men make $7 \%$ more per hour, on average, for doing the same job in a setting where work assignments are made by a gender-blind algorithm and the pay structure is tied directly to output and not negotiated. The $7 \%$ differential is as large or larger than hourly differentials in other narrowly defined, relatively homogeneous groups such as recent MBAs (Bertrand et al. (2010)) and pharmacists (Goldin and Katz (2016)), but is smaller than the differential in economy-wide samples (Blau and Kahn (2017)).

Throughout the rest of the paper, we focus on drivers in Chicago to decompose the gender gap and analyze its economic roots. This choice reduces the dataset to a more tractable size and allows for more granular data. Table 3 replicates Table 2 but limits the analysis to Chicago drivers. As the table shows, the weekly gender earnings gap in Chicago mirrors the national gap. The hourly Chicago gender earnings gap is somewhat lower, at approximately 5\%. This small difference between the national and Chicago gap is due to cross-city differences in the factors that explain the gap. We analyze these factors in detail in Chicago, which provides more insight into the roots of the gap than if we were to focus on the generally small differences across cities. Most importantly, the conclusions we draw are not sensitive to which city we analyze. 
Table 3: Chicago gender pay gap

\begin{tabular}{|c|c|c|}
\hline & $\begin{array}{c}(1) \\
\log (\text { weekly earnings })\end{array}$ & $\begin{array}{c}(2) \\
\log (\text { hourly earnings) }\end{array}$ \\
\hline isMale & $\begin{array}{l}0.4315 \\
(0.007)\end{array}$ & $\begin{array}{l}0.0485 \\
(0.001)\end{array}$ \\
\hline Intercept & $\begin{array}{l}5.0487 \\
(0.009)\end{array}$ & $\begin{array}{l}3.1151 \\
(0.001)\end{array}$ \\
\hline Week & $\mathrm{X}$ & $\mathrm{X}$ \\
\hline $\mathrm{N}$ & $1,604,627$ & $1,604,627$ \\
\hline Drivers & 120,019 & 120,019 \\
\hline$R^{2}$ & 0.038 & 0.110 \\
\hline
\end{tabular}

\section{Decomposing the Wage Gap - Chicago}

\subsection{Chicago Data and Baseline Gender Pay Gap}

By focusing attention on Chicago drivers, we can examine data at the driver-hour, rather than driver-week, level. A driver-hour is defined as a full hour block with some trip activity; for example, 8-9am on a specific Monday. We continue to restrict the data to peer-to-peer drivers in January 2015 to March 2017.

The Chicago dataset includes 120,223 drivers, 36,391 of whom are female (30.2\%). In total, we observe 33.0 million driver-hours. ${ }^{16}$ As before, we track total gross pay and hours worked for each driver-hour. We compute the implied hourly earnings in a driver-hour as total earnings for trips in that hour divided by minutes worked*60. For trips that span driver-hours, we distribute the pay uniformly between the hours based on the trip time in each hour. In Chicago, certain types of incentive earnings are paid for achieving weekly trips targets, rather than tied to individual trips. We spread these earnings uniformly across minutes worked in the week for which the incentive was earned.

Moving to driver-hour level granularity allows us to control for certain features of a driver's behavior in a given driver-hour. For example, we can now control for where a driver worked, the

\footnotetext{
${ }^{16}$ Regressions are run on a $35 \%$ subset of drivers. Results are robust to different samples.
} 
time of day and day of week, lifetime trips to-date, and whether the driver rejected a dispatch or canceled a trip that hour.

To control for driving location, we track the "geohash" where a driver is located when he or she accepts a trip. A geohash is a geocoding system that divides the world into a grid of squares of arbitrary precision. For our case, we use geohashes that are approximately three miles by three miles. Within busy areas of Chicago, this is a fairly large area and there may be differences in demand and congestion even within these areas that limit our ability to fully control for geographic effects. We have experimented with finer geographic areas and, given the conclusions do not change, we have not found this worthwhile given the additional computational complexity. We focus on the top fifty Chicago geohashes by trip density, which account for $89.2 \%$ of trips. The remaining trips are grouped into an "other" bin. For chains of UberPOOL trips, we only include the geohash of the first trip in the chain; drivers do not have control over where to locate for subsequent trips in the chain.

Before using regressions to formally decompose the gender earnings gap shown in Figure 1 (which looks nearly identical when looking only at Chicago), we examine average differences across gender in the factors that determine driver earnings. Recall from Equation 3.1 that driver earnings are a function of wait time between trips, distance to the start of the ride from where the driver accepts it, distance of the ride, speed (both on the ride and on the way to pick up the passenger), the surge rate at the time of the ride, and incentive payments.

Table 4 displays the average of these parameters by gender. Note that these averages are presented on a per-trip basis, as that is a more natural way to divide some of the parameters. Table 4 also provides an idea of the sources of the gender pay gap. First, notice that the differences are generally small. Only the difference in incentive payout is more than a few percentage points different and, given the incentive difference is nine cents while the average earnings per trip are about $\$ 10$, incentives are unlikely to drive the gap. Second, while the individual differences are small, nearly every one of the parameters favors men earning more. Men have shorter trips to the rider, longer trips, faster speed, higher surge, and more incentives. ${ }^{17}$ Women appear to have

\footnotetext{
${ }^{17}$ Equation 3.1 implies that trip distance and speed are ambiguously related to earnings; however, for the values of the other parameters that we observe in the data, earnings are almost always increasing in both distance and speed.
} 
marginally lower wait times, but the difference is neither statistically nor economically significant. The remainder of our analysis explores which of these differences in Table 4 are important drivers of the Uber gender pay gap and what underlies the differences.

Table 4: Parameter averages

\begin{tabular}{|c|c|c|c|}
\hline & Men & Women & Difference \\
\hline$w$ - Wait time (min) & $\begin{array}{c}8.223 \\
(0.008)\end{array}$ & $\begin{array}{c}8.218 \\
(0.019)\end{array}$ & -0.005 \\
\hline$d_{0}-$ Accepts-to-pickup distance (mi) & $\begin{array}{c}0.485 \\
(0.000)\end{array}$ & $\begin{array}{c}0.500 \\
(0.001)\end{array}$ & 0.015 \\
\hline$d_{1}-$ Trip distance (mi) & $\begin{array}{c}5.035 \\
(0.003)\end{array}$ & $\begin{array}{c}4.875 \\
(0.006)\end{array}$ & 0.160 \\
\hline$s-$ Speed $(\mathrm{mph})$ & $\begin{array}{l}19.532 \\
(0.006)\end{array}$ & $\begin{array}{l}18.760 \\
(0.012)\end{array}$ & 0.772 \\
\hline$S M$ - Surge multiplier & $\begin{array}{c}1.051 \\
(0.000)\end{array}$ & $\begin{array}{c}1.046 \\
(0.000)\end{array}$ & 0.005 \\
\hline$I-$ Incentive payout $(\$)$ & $\begin{array}{c}0.903 \\
(0.001)\end{array}$ & $\begin{array}{c}0.818 \\
(0.002)\end{array}$ & 0.085 \\
\hline Total per-trip payout $(\$)$ & $\begin{array}{l}10.142 \\
(0.004)\end{array}$ & $\begin{array}{c}9.841 \\
(0.008)\end{array}$ & 0.301 \\
\hline
\end{tabular}

Note: This table documents averages for men and women of the parameters in Equation 3.1. Averages are per-trip based on trips in Chicago between January-February 2017 to avoid issues with seasonality and changes in the composition of driver experience. Wait time is based on time between either coming online or completing previous trip and picking up passenger for new trip. Trip distance is based on actual route taken; however, accepts-to-pickup distance is the Haversine distance between corresponding coordinates. Standard errors in parentheses.

Table 5 refines the initial Chicago gender pay gap analysis in Table 3. However, whereas Table 3 utilized weekly observations (the hourly rate in that table is the average hourly rate for a driver in a week) to remain consistent with the regression models using the national data, Table 5 uses driver-hour observations.

Column 1 of Table 5 reveals a baseline Chicago gender pay gap of $3.6 \%$ at the driver-hour level, controlling only for overall conditions in a given week. ${ }^{18}$ Column 2 adds 168 indicator variables for the hour of week. Note that this increases the R-square of the regression quite substantially, which is what we would expect given that Chen et al. (2017) show substantial heterogeneity in Uber driver earnings by hour of week. ${ }^{19}$ These hour of week controls eliminate $14 \%$ of the gender pay

\footnotetext{
${ }^{18}$ This number is lower than the corresponding estimate in Table 3 because the weighting is by driver-hour rather than driver-week, effectively up-weighting drivers who work more hours in a week. This affects the measured gap for reasons similar to those we discuss below as we decompose the gap.

${ }^{19}$ See also Appendix Table 7.
} 
Table 5: Baseline gender pay gap

\begin{tabular}{|c|c|c|c|c|c|c|}
\hline & (1) & (2) & (3) & (4) & (5) & (6) \\
\hline isMale & $\begin{array}{l}0.0356 \\
(0.003)\end{array}$ & $\begin{array}{l}0.0302 \\
(0.003)\end{array}$ & $\begin{array}{l}0.0261 \\
(0.002)\end{array}$ & $\begin{array}{l}0.0220 \\
(0.002)\end{array}$ & $\begin{array}{l}0.0210 \\
(0.002)\end{array}$ & $\begin{array}{l}0.0210 \\
(0.002)\end{array}$ \\
\hline riderCancellations & & & & & & $\begin{array}{c}-0.0478 \\
(0.000)\end{array}$ \\
\hline driverCancellations & & & & & & $\begin{array}{l}-0.0302 \\
(0.0003)\end{array}$ \\
\hline Intercept & $\begin{array}{l}3.0862 \\
(0.003)\end{array}$ & $\begin{array}{l}3.0912 \\
(0.003)\end{array}$ & $\begin{array}{l}3.0946 \\
(0.003)\end{array}$ & $\begin{array}{l}3.0980 \\
(0.002)\end{array}$ & $\begin{array}{l}3.0989 \\
(0.002)\end{array}$ & $\begin{array}{l}3.1081 \\
(0.002)\end{array}$ \\
\hline Week & $\mathrm{X}$ & $\mathrm{X}$ & $\mathrm{X}$ & $\mathrm{X}$ & $\mathrm{X}$ & $\mathrm{X}$ \\
\hline Hour of week & & $\mathrm{X}$ & & $\mathrm{X}$ & $\mathrm{X}$ & $\mathrm{X}$ \\
\hline Geohash & & & $\mathrm{X}$ & $\mathrm{X}$ & $\mathrm{X}$ & $\mathrm{X}$ \\
\hline Geohash*hour of week & & & & & $\mathrm{X}$ & $\mathrm{X}$ \\
\hline $\mathrm{N}$ & $11,572,163$ & $11,572,163$ & $11,572,163$ & $11,572,163$ & $11,572,163$ & $11,572,163$ \\
\hline$R^{2}$ & 0.039 & 0.099 & 0.092 & 0.143 & 0.161 & 0.164 \\
\hline
\end{tabular}

Note: This table documents the evolution of the gender pay gap as time and location covariates are added. Data are at the driver-hour level. The outcome variable is log of hourly earnings. Hour of week controls for each of 168 hours. Geohash controls are a vector of dummies for whether a driver began a trip in a given geohash. To keep computations tractable, we include the top 50 geohashes in Chicago (which covers almost $90 \%$ of trips); trips beginning in other geohashes are captured by an 'other' dummy. Standard errors (clustered at the driver-level) in parentheses.

gap. This suggests that, while the variation in preferences documented by Chen et al. (2017) may be correlated with gender, hour-within-week preference differences are a small part of the gender gap. If female drivers receive more non-pecuniary benefits than men from picking which hours to work, they do not pay a large financial price for this flexibility.

Column 3 of Table 5 adds controls for the top fifty Chicago geohashes. This removes about a quarter of the gender pay gap, indicating that men drive in the parts of Chicago where pay is higher due to factors such as higher surge and shorter waiting times. Per Column 4, the "where and when" variables combined attenuate the gender earnings gap by about a third; in a later section, we more rigorously decompose how each factor independently contributes to explaining the earnings gap. Column 5 shows that there is no additional explanatory power from the interaction of location and hour, suggesting perhaps surprisingly that the hour of week earnings differentials are fairly consistent across areas of Chicago.

While the Uber rider/driver matching algorithm is gender-neutral, customer discrimination could contribute to Uber gender pay differences if riders disproportionately cancel trips when paired 
with a female driver. ${ }^{20}$ After requesting a trip, riders see the name and a small image of the driver and can choose to cancel the trip. To determine the potential impact of customer (and driver) discrimination, we control for cancellations in Column 6 of Table 5 and show that customer discrimination does not contribute to the gender pay gap. ${ }^{21}$

Overall, Table 5 shows that time and location explain some of the gender earnings gap but most of it remains unexplained. The remaining gender earnings differential of $2.1 \%$ is small compared with overall gender pay gaps measured in the literature, but it is substantial given we are exploring a group of heterogeneous workers doing exactly the same job at the same time and location and being paid by a gender-blind algorithm.

\subsection{Returns to Experience}

As shown by Bertrand et al. (2010), gender differences in experience can be an important contributor to gender pay gaps and, as shown by Goldin and Katz (2016), the gender earnings gap can be relatively small if a profession has low penalties for part-time work. Though not examining gender, Haggag et al. (2017) show that learning-by-doing and experience are important for New York City taxi drivers. While drivers on Uber may learn in some ways similar to taxi drivers, there are likely important differences. For example, Uber rates fluctuate with surge prices (unlike fixed taxi fares), Uber uses an assignment algorithm to offer trips to drivers, drivers use GPS, and drivers are not customarily paid a tip.

We build on this past work on gender differences in experience and on driver learning by measuring how experience affects Uber driver earnings and exploring the relationship between learning, gender, and pay. An important consideration is that while Uber pays according to a fixed formula, many of the parameters of the formula (that is, the variables listed in Table 4) are within the driver's control. For example, drivers can indirectly affect the surge multiplier and wait times

\footnotetext{
${ }^{20}$ Though many studies have hypothesized about customer discrimination and hypothesized that wage residuals may be due to customer preferences (especially race-based discrimination), prior work has not been able to conclusively establish if or when customer discrimination contributes to gender pay gaps.

${ }^{21}$ In the average driver-hour, total cancellation rates are roughly equivalent between men and women.
} 
by choosing where and when to work and directly affect their driving speed by simply driving faster. As drivers work more, they can begin to learn optimal driving behaviors to maximize earnings. ${ }^{22}$

Figure 2 provides a visual indication of why possible returns to experience can affect the gender earnings gap. The figure, which shows the average tenure of all drivers with a completed trip in January 2017, reveals that men are far more likely to have been driving on Uber for over 2 years. Women are likely to have joined in recent months. Further, Figure 3 shows that men accumulate completed trips at a faster rate than women. Interestingly, just as with Chicago MBAs (Bertrand et al. (2010)), male drivers accumulate more experience by being more likely to work continuously and by working more hours conditional on working.

Figure 4 demonstrates the raw driver returns to experience as measured by cumulative number of trips driven. There is a clear learning curve, which is especially steep early in a driver's tenure. Drivers continue to learn valuable skills on the job through at least 2,500 trips with a fully experienced driver earning about $\$ 3$ per hour (more than 10\%) more than a driver in his or her first 500 trips. In principle, the rise in earnings shown in Figure 4 could be a selection effect if better drivers last longer on the Uber platform. While there is some degree of selection into staying on the platform based on earnings, Figure 4 looks identical if we limit the graph to drivers that complete at least 1,000 trips or that drive for Uber for at least six months. This suggests the pattern in Figure 4 is a true learning effect. We discuss possible selection in learning in more depth in the appendix.

In Table 6, we return to our earnings regression and show that there are substantial returns to experience on Uber. Column 1 shows that drivers who have completed over 2500 trips make nearly $14 \%$ more than those in their first 100 trips. Gender differences in average experience are clearly important as, controlling for experience, the gender earnings gap shrinks to $1.4 \%$ or roughly a third of the initial earnings gap in Chicago. ${ }^{23}$

\footnotetext{
${ }^{22}$ Another activity that may generate a return to experience is "dual-apping," which is when drivers accept trips from both Uber and a competitor (primarily Lyft). Dual-apping has the potential to increase earnings due to less time waiting for a dispatch and the ability to filter higher-value trips if the surge multiplier differs across platforms. We do not have a credible way to determine the degree to which this affects earnings nor whether specific drivers are dual-apping, so we cannot isolate dual-apping's contribution to the return to experience.

${ }^{23}$ These five bins of experience capture the relevant value of experience. We have experimented with other parametric forms of experience in these regressions and the results are qualitatively similar.
} 
Figure 2: Distribution of driver tenure, January 2017

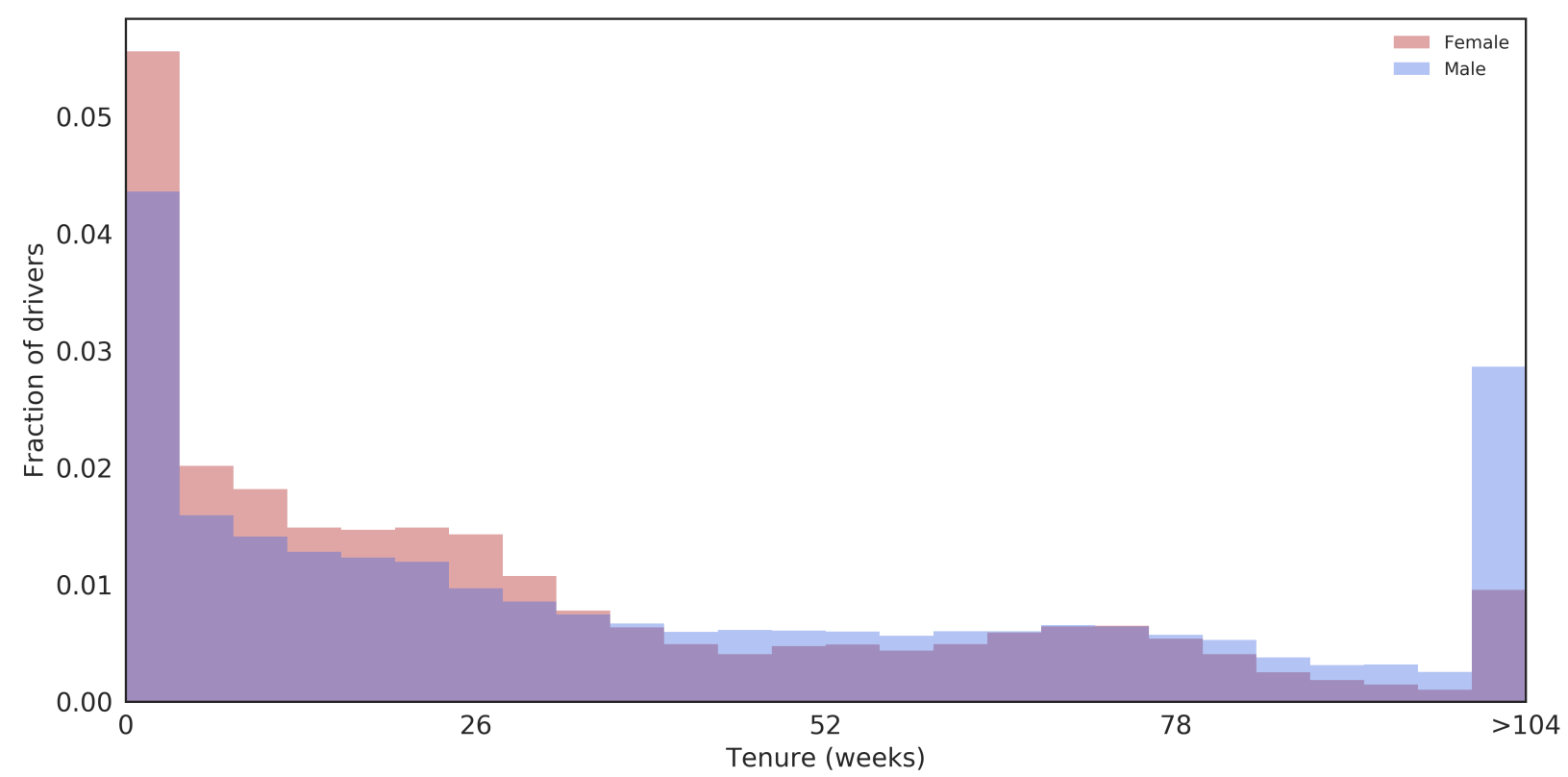

Note: This figure shows the average weeks of tenure for drivers that completed a trip in January 2017; we limit to a single month to avoid composition effects. Tenure is measured as the number of weeks since a driver's first completed trip.

Figure 3: Accumulation of trips over weeks of driving

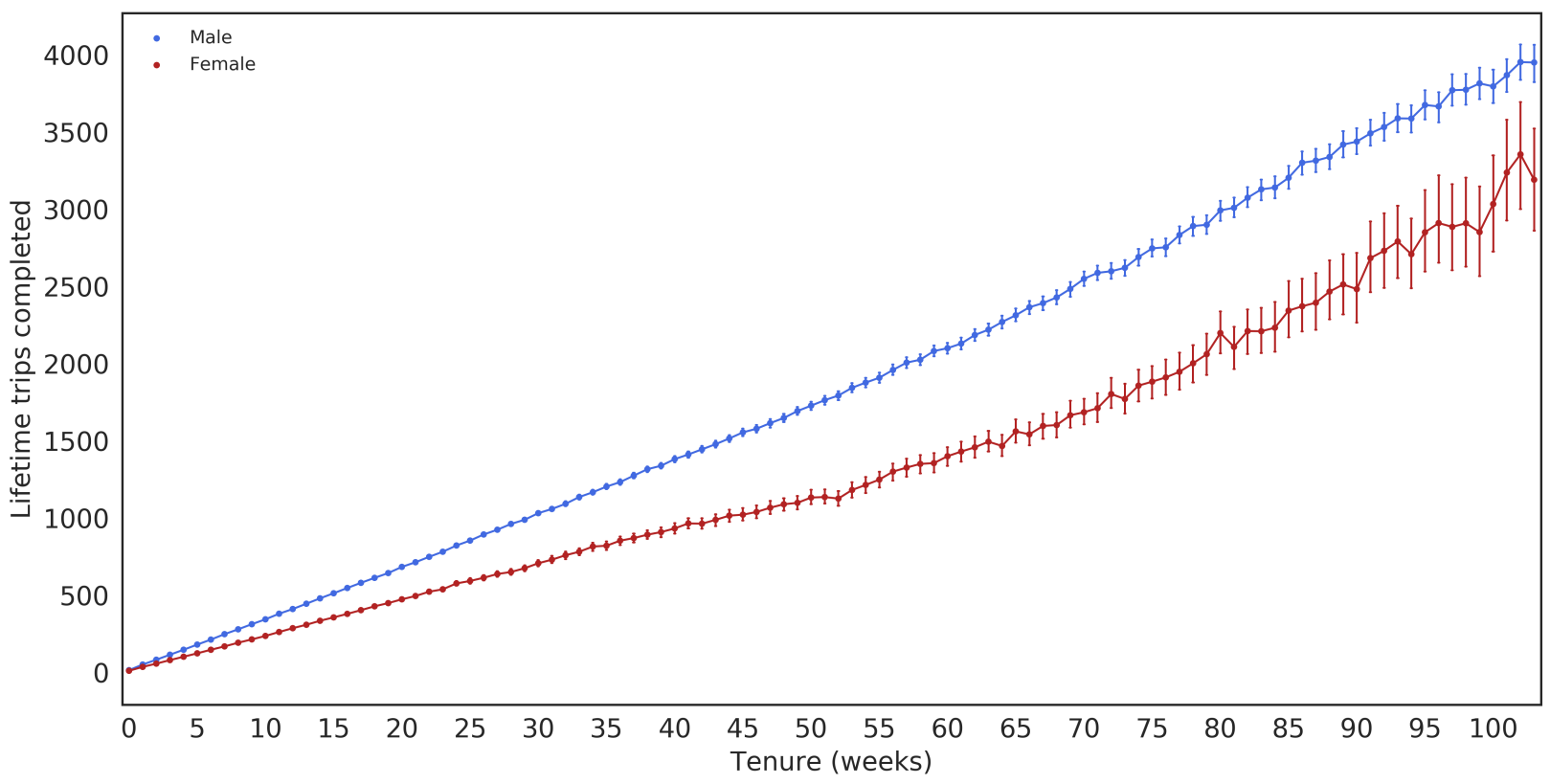

Note: This figure shows the average number of lifetime trips completed for drivers of a certain tenure. Tenure is based on the number of weeks since a driver completed their first trip. The data only include driver-weeks with $>0$ trips. 
Figure 4: Returns to experience

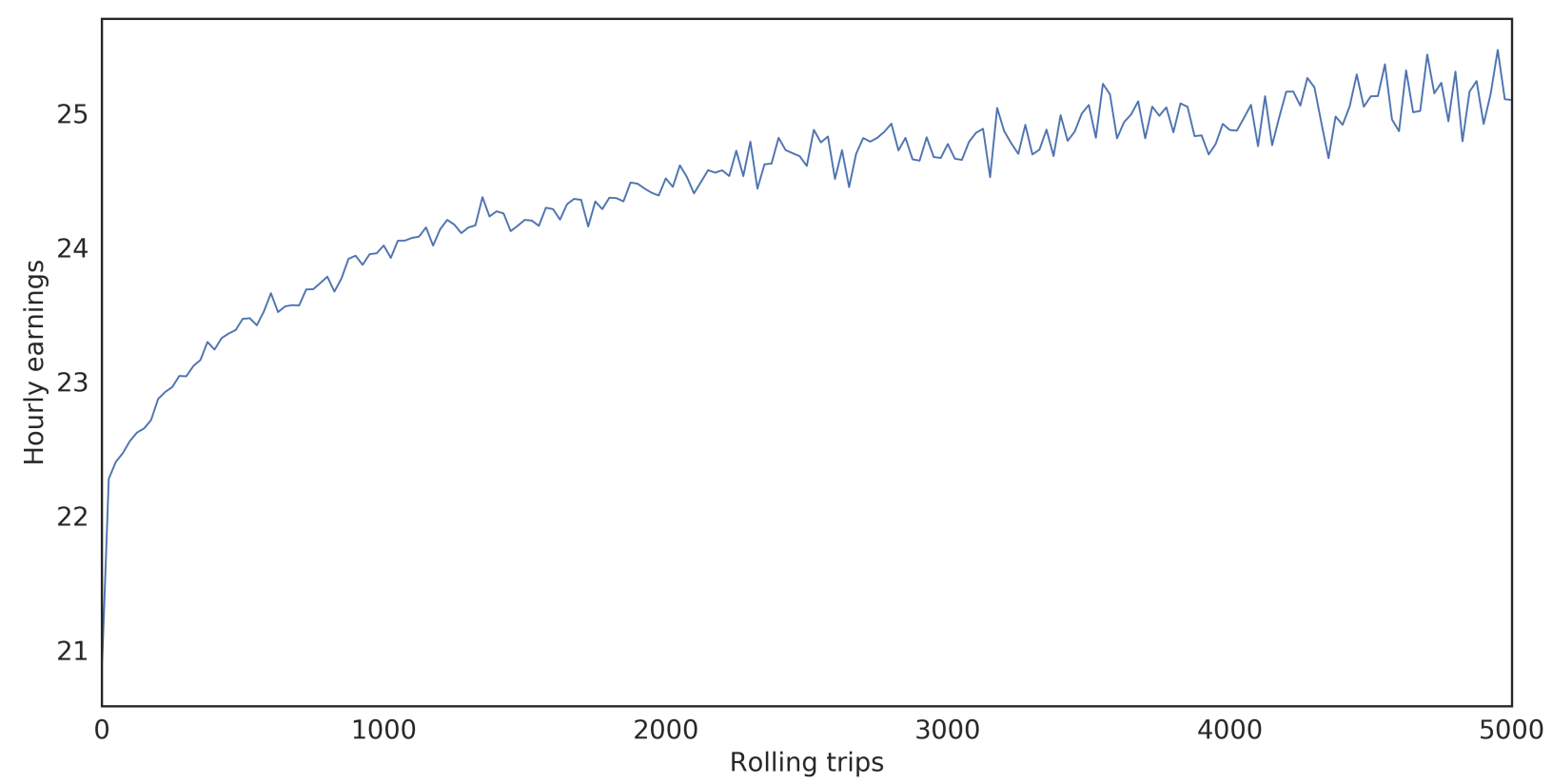

Note: This figure shows the average earnings of drivers with a given number of rolling trips completed prior to a day of work; rolling trips are binned into buckets of 25 trips completed. Data include all Chicago drivers from January 2015 to March 2017.

With controls for hour of week (Column 2), the gender gap is further reduced to under 1\%, but the returns to experience do not change noticeably. On the other hand, controls for driver location (Column 3) do not reduce the gender gap but substantially reduce the returns to experience. Combined, these two columns suggest that the primary effect of experience on earnings comes from learning where to drive and that men and women have differences in terms of their taste for when to drive. Overall, the table shows that men and women, through having been on Uber for different lengths of time and accumulating experience at different rates, are on different parts of the learning curve, which drives a large part of the gender earnings gap. ${ }^{24}$

In addition to deciding where and when to drive, drivers can affect their earnings through strategic actions. We consider two such strategic actions: rejecting dispatches and canceling trips. When drivers receive a dispatch, they are told where the rider is and the estimated time-to-pickup. They can then choose to accept or reject the dispatch. This information can be valuable in assessing the quality of a given dispatch. If a rider is particularly far away, then there is an additional cost;

\footnotetext{
${ }^{24}$ As shown in Appendix Table 14, men and women are not learning at different rates.
} 
recall that drivers are not compensated for the time it takes to drive to meet a rider. ${ }^{25}$ If a driver has reason to think that, by rejecting a ride, he or she will be offered a closer dispatch shortly, that driver may be able to increase expected earnings by not accepting the first dispatch. Savvy drivers will also realize that a high time-to-pickup ride may indicate an imbalance in supply and demand that may soon be corrected by a higher surge. ${ }^{26}$

Once a driver accepts a dispatch, the driver can cancel the trip before picking up the rider. After accepting, drivers are able to contact the rider. Some may do so to learn about the rider destination - for example, calling and asking if the rider is headed to the airport - and canceling if the driver believes the trip will not be worth the time. ${ }^{27}$ Experienced drivers may also learn to cancel when they have reason to believe the rider will not show up.

Table 7 adds dummy variables that indicate whether a driver rejected a dispatch or canceled a trip during a given driver-hour to our prior regressions. Controlling for time and geography, there is a negative impact on earnings of rejecting a dispatch or canceling a trip. However, this negative effect decreases as experience increases (while still remaining negative). Receiving a bad draw dispatch can never have a positive effect on earnings. A driver either completes the trip, which likely took longer than it was worth, or recognizes that it was a bad draw, rejects or cancels it, and then must wait for the next dispatch. As drivers gain experience, they can more accurately estimate the trade-off between rejecting and having to wait for a new dispatch versus accepting and completing a potentially low value trip.

These and earlier regressions show that drivers become more productive (and earn more) as they learn where to drive, when to drive, and how to strategically cancel and accept trips. However, even with controls for strategic rejecting and canceling, drivers with over 2500 trips make $6.2 \%$ more than those in their first 100 trips; there are substantial (but smaller) returns to experience that remain unexplained.

\footnotetext{
${ }^{25}$ Effective October 2017, Uber initiated a system where drivers are paid (and riders are charged) for particularly long pickups.

${ }^{26}$ Surge rates update every two minutes.

${ }^{27}$ While this is feasible, it is against Uber's community guidelines, which prohibit "destination discrimination," and may result in deactivation. It is unclear how stringently these guidelines are enforced as identifying true destination discrimination is likely difficult.
} 
While Table 7 sheds light on the driver learning process, these regressions leave the Uber gender pay gap unaffected. There are returns to learning how to reject/cancel, which affect men and women differently because of their correlation with driver experience. However, holding driver experience constant, men and women do not differentially accept or reject trips in a way that affects their pay. In all of our analyses, there are no gender differences in the learning process. Learning affects the gender gap because, though each additional ride teaches men and women the same valuable skills, men accumulate ride experience (and, therefore, information) faster than women.

Overall, we conclude that, even in this short-term gig economy environment, experience and gender differences in experience play out in a way that contributes substantially to the gender pay gap, as men and women are on different parts of the learning curve. On balance, the relationship between experience and the gender pay gap for drivers is surprisingly similar to at least some traditional job environments.

Table 6: Returns to experience

\begin{tabular}{|c|c|c|c|c|}
\hline & $(1)$ & $(2)$ & $(3)$ & $(4)$ \\
\hline isMale & $\begin{array}{l}0.0138 \\
(0.003)\end{array}$ & $\begin{array}{l}0.0083 \\
(0.003)\end{array}$ & $\begin{array}{l}0.0129 \\
(0.003)\end{array}$ & $\begin{array}{l}0.0081 \\
(0.002)\end{array}$ \\
\hline Trips completed: $100-500$ & $\begin{array}{l}0.0530 \\
(0.001)\end{array}$ & $\begin{array}{l}0.0497 \\
(0.001)\end{array}$ & $\begin{array}{l}0.0357 \\
(0.001)\end{array}$ & $\begin{array}{l}0.0339 \\
(0.001)\end{array}$ \\
\hline Trips completed: $500-1000$ & $\begin{array}{l}0.0773 \\
(0.002)\end{array}$ & $\begin{array}{l}0.0747 \\
(0.002)\end{array}$ & $\begin{array}{l}0.0512 \\
(0.002)\end{array}$ & $\begin{array}{l}0.0495 \\
(0.001)\end{array}$ \\
\hline Trips completed: $1000-2500$ & $\begin{array}{l}0.1001 \\
(0.002)\end{array}$ & $\begin{array}{l}0.0990 \\
(0.002)\end{array}$ & $\begin{array}{l}0.0650 \\
(0.002)\end{array}$ & $\begin{array}{l}0.0638 \\
(0.002)\end{array}$ \\
\hline Trips completed: $>2500$ & $\begin{array}{l}0.1391 \\
(0.004)\end{array}$ & $\begin{array}{l}0.1390 \\
(0.003)\end{array}$ & $\begin{array}{l}0.0877 \\
(0.003)\end{array}$ & $\begin{array}{l}0.0860 \\
(0.003)\end{array}$ \\
\hline Intercept & $\begin{array}{l}3.0228 \\
(0.002)\end{array}$ & $\begin{array}{l}3.0294 \\
(0.001)\end{array}$ & $\begin{array}{l}3.0528 \\
(0.003)\end{array}$ & $\begin{array}{l}3.0581 \\
(0.001)\end{array}$ \\
\hline Week & $\mathrm{X}$ & $\mathrm{X}$ & $\mathrm{X}$ & $\mathrm{X}$ \\
\hline Hour of week & & $\mathrm{X}$ & & $\mathrm{X}$ \\
\hline Geohash & & & $\mathrm{X}$ & $\mathrm{X}$ \\
\hline Geohash*hour of week & & & & $\mathrm{X}$ \\
\hline $\mathrm{N}$ & $11,572,163$ & $11,572,163$ & $11,572,163$ & $11,572,163$ \\
\hline$R^{2}$ & 0.048 & 0.107 & 0.096 & 0.165 \\
\hline
\end{tabular}


Table 7: Returns to strategic rejecting and canceling

\begin{tabular}{|c|c|c|}
\hline & $(1)$ & $(2)$ \\
\hline isMale & $\begin{array}{l}0.0142 \\
(0.003)\end{array}$ & $\begin{array}{l}0.0093 \\
(0.002)\end{array}$ \\
\hline Trips completed: $100-500$ & $\begin{array}{l}0.0471 \\
(0.001)\end{array}$ & $\begin{array}{l}0.0282 \\
(0.001)\end{array}$ \\
\hline Trips completed: $500-1000$ & $\begin{array}{l}0.0681 \\
(0.002)\end{array}$ & $\begin{array}{l}0.0414 \\
(0.001)\end{array}$ \\
\hline Trips completed: $1000-2500$ & $\begin{array}{l}0.0875 \\
(0.002)\end{array}$ & $\begin{array}{l}0.0542 \\
(0.002)\end{array}$ \\
\hline Trips completed: $>2500$ & $\begin{array}{l}0.1192 \\
(0.004)\end{array}$ & $\begin{array}{l}0.0619 \\
(0.003)\end{array}$ \\
\hline rejectDispatch & $\begin{array}{c}-0.0757 \\
(0.001)\end{array}$ & $\begin{array}{c}-0.1151 \\
(0.001)\end{array}$ \\
\hline rejectDispatch*Trips completed: $100-500$ & $\begin{array}{l}0.0234 \\
(0.002)\end{array}$ & $\begin{array}{l}0.0211 \\
(0.002)\end{array}$ \\
\hline rejectDispatch*Trips completed: 500-1000 & $\begin{array}{l}0.0367 \\
(0.002)\end{array}$ & $\begin{array}{l}0.0319 \\
(0.002)\end{array}$ \\
\hline rejectDispatch*Trips completed: $1000-2500$ & $\begin{array}{l}0.0520 \\
(0.003)\end{array}$ & $\begin{array}{l}0.0430 \\
(0.002)\end{array}$ \\
\hline rejectDispatch ${ }^{*}$ Trips completed: $>2500$ & $\begin{array}{l}0.0765 \\
(0.004)\end{array}$ & $\begin{array}{l}0.0619 \\
(0.003)\end{array}$ \\
\hline cancelTrip & $\begin{array}{c}-0.0227 \\
(0.002)\end{array}$ & $\begin{array}{c}-0.0841 \\
(0.002)\end{array}$ \\
\hline cancelTrip*Trips completed: $100-500$ & $\begin{array}{l}0.0112 \\
(0.003)\end{array}$ & $\begin{array}{l}0.0131 \\
(0.003)\end{array}$ \\
\hline cancelTrip*Trips completed: $500-1000$ & $\begin{array}{l}0.0242 \\
(0.004)\end{array}$ & $\begin{array}{l}0.0275 \\
(0.003)\end{array}$ \\
\hline cancelTrip*Trips completed: 1000-2500 & $\begin{array}{l}0.0206 \\
(0.003)\end{array}$ & $\begin{array}{l}0.0356 \\
(0.003)\end{array}$ \\
\hline cancelTrip*Trips completed: >2500 & $\begin{array}{l}0.0462 \\
(0.004)\end{array}$ & $\begin{array}{l}0.0557 \\
(0.004)\end{array}$ \\
\hline Intercept & $\begin{array}{l}3.0400 \\
(0.003)\end{array}$ & $\begin{array}{l}3.0872 \\
(0.002)\end{array}$ \\
\hline Week & $\mathrm{X}$ & $\mathrm{X}$ \\
\hline Geohash*hour of week & & $\mathrm{X}$ \\
\hline $\begin{array}{l}\mathrm{N} \\
R^{2}\end{array}$ & $\begin{array}{c}11,572,163 \\
0.049\end{array}$ & $\begin{array}{c}11,572,163 \\
0.171\end{array}$ \\
\hline
\end{tabular}

Note: This table expands on the regressions in Table 6 by adding covariates for whether a driver rejected a dispatch or canceled a trip in a given hour. Data are at the driver-hour level. The outcome variable is log of hourly earnings. Standard errors (clustered at the driver-level) in parentheses. 


\subsection{Returns to Speed}

As shown in Equation 3.1, drivers earn a per-minute and a per-mile rate on each trip. These rates may be balanced such that there is a return to speed. If Uber paid only per-minute, earningsmaximizing drivers would drive as slowly as possible (at least until the disutility of the rider anger exceeds utility from earnings).

The returns to speed will depend on market conditions, such as the expected wait time for a new dispatch. In some unusual circumstances, there are negative returns to speed as the per-minute rates can be relatively valuable if the driver expects to wait a long time until getting another fare. In general, the rates and wait times in our data are such that there is a positive expected return to driving faster. This return is somewhat higher when driver wait times are shorter. At extreme speeds, the returns to speed net of costs may turn negative if the risk of a collision or a speeding ticket becomes high enough.

Given that prior research suggests men are more risk tolerant and aggressive than women (see Bertrand (2011) and, in the context of driving, Dohmen et al. (2011)) and that Table 4 shows that male drivers drive faster than women, we now investigate how driver speed affects the gender earnings gap. We measure speed as distance on trip divided by time on trip in a given driver-hour. Table 8 adds the log of speed as an explanatory variable to our earlier hourly pay regressions.

Control variables are important in this regression, because higher pay areas and times of week in Chicago (those areas where there is a more constant stream of fares and where surge is likely to be higher) are also likely more congested, which lowers speed. The coefficient on log speed in Column 1 of Table 8 suggests an elasticity of $27 \%$ of speed on earnings; a $1 \%$ increase in speed increases earnings by $0.27 \%$. In Column 2, when we control for geohash and hour of week (thus removing the fact that congestion both lowers speeds and increases earnings), this number increases to $46 \%$. Column 2 shows that controlling for speed and neighborhood reduces our original $3.6 \%$ gender pay gap all the way to just $1 \%$. Adding the learning-by-doing experience variables to this model fully eliminates the gender pay gap. ${ }^{28}$

\footnotetext{
${ }^{28}$ The estimate in Column 4 is very precise; the gender pay gap has a $95 \%$ confidence interval of $-0.6 \%$ to $0.2 \%$.
} 
We believe we can describe this speed difference across genders primarily as a difference in taste that happens to have a productive value on Uber rather than a response by male drivers to the incentive to drive faster. ${ }^{29}$ First, as mentioned above, others have shown that men are more risk tolerant, both in general and when driving in particular. Second, when we analyze Uber driver speed as a function of gender, experience, and time/location, we find that men drive $2.2 \%$ faster than women. ${ }^{30}$ Further, speed is only slightly increasing in experience (and experience does little to close the gender speed gap); if drivers were responding strongly to the incentive to drive faster, we might expect that their speed increases substantially with experience on the platform.

In addition, we gathered data from the National Highway Travel Survey a nationally-representative survey that gathers demographics, vehicle ownership, and "trip diaries" from 150,000 households. Outside of Uber, there is rarely a pecuniary incentive to drive faster. Despite this, we find that men still drive faster in the NHTS sample (details in Appendix Table 17). Gender differences in the taste for speed are a general population phenomenon that have labor market value to drivers.

\section{Summarizing the Decomposition}

Using standard pay regressions, we have fully explained the gender earnings gap for drivers on Uber. The raw gap in Chicago of approximately four percent can be attributed to three factors: male preference for faster driving, time and location choices of drivers, and higher average male on-the-job experience.

To measure the extent to which each of these factors contributes to the gender pay gap, we follow the approach described in Gelbach (2016). ${ }^{31}$ Conceptually, this approach treats each factor as an "omitted variable" in the relationship between earnings and gender and measures the bias that would result if the factor were excluded. This allows us to disentangle the impact on the gender gap of each factor we controlled for sequentially in the above section, invariant of the order in which we

\footnotetext{
${ }^{29}$ Speed is productive in that it generates earnings for both Uber and the driver on any given ride. It also may generate at least a small long-term value for Uber (and a positive externality on other drivers) because passenger ratings of drivers are increasing in driver speed, holding other factors constant. This relationship is highly significant statistically but small in magnitude.

${ }^{30}$ See Appendix Table 16 for details.

${ }^{31}$ See Allcott et al. (2017) or Buckles and Hungerman (2013) for examples of the Gelbach decomposition in practice.
} 
Table 8: Returns to speed

\begin{tabular}{|c|c|c|c|c|c|c|}
\hline & $(1)$ & $(2)$ & $(3)$ & $(4)$ & $(5)$ & $(6)$ \\
\hline isMale & $\begin{array}{l}0.0256 \\
(0.004)\end{array}$ & $\begin{array}{l}0.0106 \\
(0.002)\end{array}$ & $\begin{array}{l}0.0101 \\
(0.002)\end{array}$ & $\begin{array}{l}0.0016 \\
(0.002)\end{array}$ & $\begin{array}{c}-0.0018 \\
(0.002)\end{array}$ & $\begin{array}{c}-0.0019 \\
(0.002)\end{array}$ \\
\hline logSpeed & $\begin{array}{l}0.2677 \\
(0.002)\end{array}$ & $\begin{array}{l}0.4552 \\
(0.001)\end{array}$ & $\begin{array}{l}0.4623 \\
(0.001)\end{array}$ & $\begin{array}{l}0.2715 \\
(0.002)\end{array}$ & $\begin{array}{l}0.4544 \\
(0.001)\end{array}$ & $\begin{array}{l}0.4616 \\
(0.001)\end{array}$ \\
\hline Trips completed: $100-500$ & & & & $\begin{array}{l}0.0563 \\
(0.001)\end{array}$ & $\begin{array}{l}0.0318 \\
(0.001)\end{array}$ & $\begin{array}{l}0.0321 \\
(0.001)\end{array}$ \\
\hline Trips completed: $500-1000$ & & & & $\begin{array}{l}0.0819 \\
(0.002)\end{array}$ & $\begin{array}{l}0.0460 \\
(0.001)\end{array}$ & $\begin{array}{l}0.0460 \\
(0.001)\end{array}$ \\
\hline Trips completed: $1000-2500$ & & & & $\begin{array}{l}0.1075 \\
(0.003)\end{array}$ & $\begin{array}{l}0.0599 \\
(0.002)\end{array}$ & $\begin{array}{l}0.0594 \\
(0.002)\end{array}$ \\
\hline Trips completed: $>2500$ & & & & $\begin{array}{l}0.1519 \\
(0.004)\end{array}$ & $\begin{array}{c}0.0831 \\
(0.0003)\end{array}$ & $\begin{array}{l}0.0810 \\
(0.003)\end{array}$ \\
\hline Intercept & $\begin{array}{l}2.3084 \\
(0.003)\end{array}$ & $\begin{array}{l}1.7704 \\
(0.004)\end{array}$ & $\begin{array}{l}1.7502 \\
(0.006)\end{array}$ & $\begin{array}{l}2.2293 \\
(0.005)\end{array}$ & $\begin{array}{l}1.7346 \\
(0.004)\end{array}$ & $\begin{array}{l}1.7083 \\
(0.004)\end{array}$ \\
\hline Week & $\mathrm{X}$ & $\mathrm{X}$ & $\mathrm{X}$ & $\mathrm{X}$ & $\mathrm{X}$ & $\mathrm{X}$ \\
\hline Hour of week & & $\mathrm{X}$ & $\mathrm{X}$ & & $\mathrm{X}$ & $\mathrm{X}$ \\
\hline Geohash & & $\mathrm{X}$ & $\mathrm{X}$ & & $\mathrm{X}$ & $\mathrm{X}$ \\
\hline Geohash*hour of week & & & $\mathrm{X}$ & & & $\mathrm{X}$ \\
\hline $\mathrm{N}$ & $11,572,163$ & $11,572,163$ & $11,572,163$ & $11,572,163$ & $11,572,163$ & $11,572,163$ \\
\hline$R^{2}$ & 0.101 & 0.263 & 0.282 & 0.111 & 0.266 & 0.284 \\
\hline
\end{tabular}

Note: The table expands on earlier regressions by adding log speed as an explanatory variable. Speed is based on total trip distance and duration in a given driver-hour. The outcome variable is log of hourly earnings. Standard errors (clustered at the driver-level) in parentheses. 
initially added them into our baseline regression specification. This approach is of particular value when our observables are correlated; for example, our measure of driving speed is likely endogenous with where/when a driver works such that the difference in the point estimates of the pay gap with and without controlling for speed is likely also capturing differences in where/when drivers work.

More precisely, consider a regression of the form

$$
\ln \left(\text { Earnings }_{d t}\right)=\beta \text { isMale }_{d}+\gamma_{v} X_{v d t}+\gamma_{2} X_{2 d t}+\epsilon_{d}
$$

where $X_{v}$ is single vector for variable $v$ and $X_{2}$ captures all remaining variables in our full model (i.e. speed, experience indicators, time indicators, and location indicators). Now suppose we ignore information contained in $X_{v}$. The resulting omitted variable bias is given by $\hat{\pi}_{v}=\hat{\Gamma}_{v} \hat{\gamma}_{v}$ where $\hat{\Gamma}_{v}$ is estimated using an auxiliary regression of gender on $X_{v}$.

Dividing our estimate of omitted variable bias by $\hat{\beta}^{\text {base }}$, the baseline relationship between earnings and gender conditioning only on calendar week, gives us an estimate of the variable's contribution to the gender pay gap:

$$
\tilde{\pi}_{v}=\frac{\hat{\pi}_{v}}{\hat{\beta}^{\text {base }}}
$$

These contributions can be aggregated across vectors of variables, such as each of 168 indicators for hour of week, to obtain the combined contribution of controlling for all hour of week indicators. We do this for hour of week (when), geohash (where), bins of experience, and speed.

Figure 5 presents the parameter estimates of Equation 5.2, along with 95\% confidence intervals, corresponding to a decomposition of the change in point estimates between our baseline model, which includes only controls for the week of the data (see Column 1, Table 5), and a fully specified model with controls for speed, location, time of week, and experience (see Column 5, Table 8). Speed alone explains nearly half the gap (48\%). Experience can explain the next largest share, at $36 \%$. Where drivers work can explain a further $28 \%$ of the gap, while time of week-once conditioning out the other factors - actually widens the pay gap (-7\%). This suggests that while women may choose to drive at different times of the week than men, they do not pay a steep penalty for this flexibility. The attenuation in the gender pay gap observed when hour of week controls are 
included (Table 5) is due to factors, such as experience and driving location, correlated with when drivers work. Together, these factors fully explain the gender pay gap amongst drivers. ${ }^{32}$

On the one hand, it is somewhat surprising that we can fully explain the gap as we are not aware of prior cross-sectional wage regressions that have precisely and entirely eliminated the gender pay gap in virtually any context. On the other hand, it is also somewhat surprising that there was a gender earnings gap to begin with given Uber rides are allocated algorithmically in a nondiscriminatory manner.

To further identify the underlying sources of the differences in pay by gender, we return to our table of averages of all the parameters that enter into driver earnings, as described in Equation 3.1. Table 9 shows the average of each parameter by gender for drivers of three different levels of experience. All the observations are from a short cross-section so as to control for conditions that affect earnings.

The table highlights three important themes from our analysis. First, both men and women learn in a productive manner and at roughly the same rate in terms of number of rides. The wait times go down by about 5-10\% over 1,500 rides of experience. Surge rates improve for both genders and are nearly identical for the two genders. Men have slightly longer pickup distances and ride distances throughout, but both genders lower pickup distances and increase trip distances in a similar manner. ${ }^{33}$

Speed is an outlier in that there is not a clear "improvement" over time for drivers. This is likely because drivers learn that more congested areas are more lucrative. As per our regressions, there is a noteworthy (if not huge) difference in speed by gender that is consistent over tenure.

Table 9 captures the important effects of learning. While men and women learn at the same per-ride rate, the driving schedules of men mean that they learn, on average, more intensively per week of experience, which generates a gender pay gap. The table also captures that, at all tenures, men prefer to drive faster.

\footnotetext{
${ }^{32}$ The results sum to slightly greater than $100 \%$ as the point estimate on isMale is (insignificantly) negative after controlling for each of the covariates.

${ }^{33}$ The distance differences seem to be related to men having a stronger preference for airport trips, possibly due to the fact that they work longer shifts and are, therefore, more willing to stray from their base location.
} 
Figure 5: Gelbach decomposition

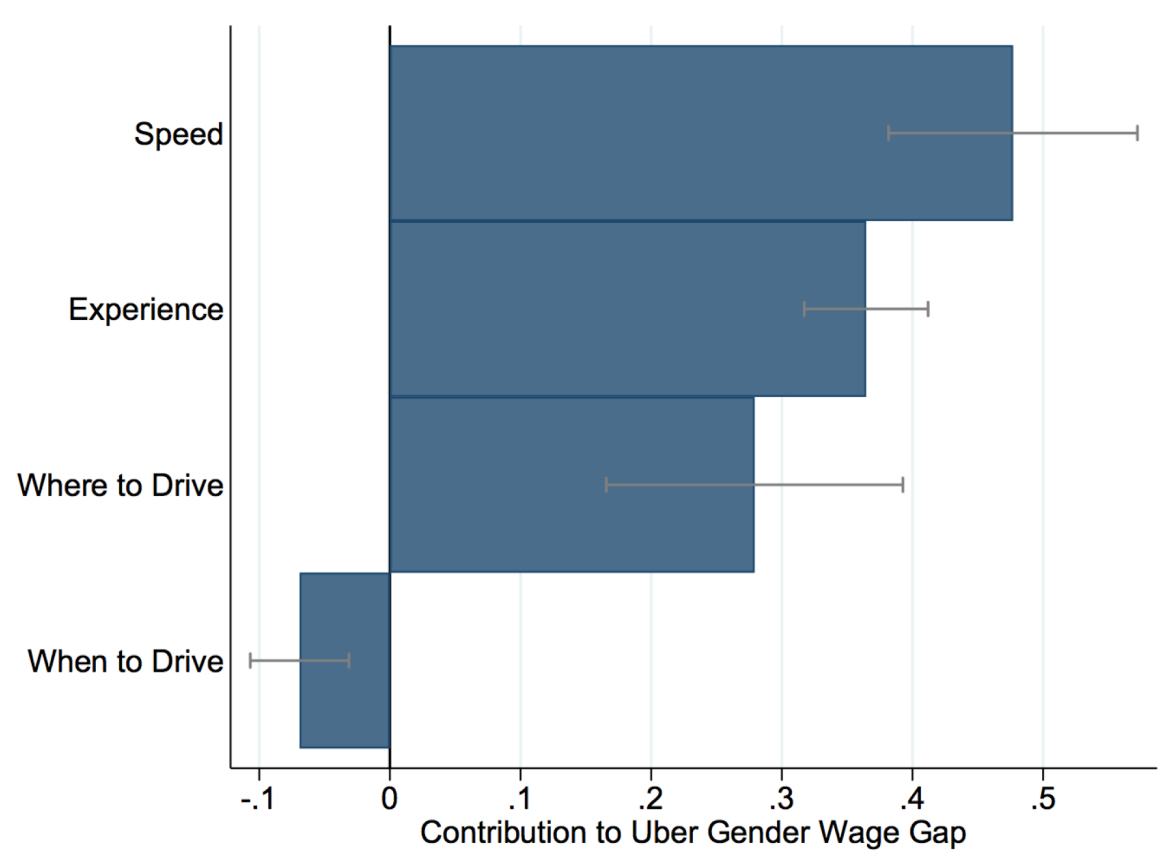

Note: This figure uses the method described in Gelbach (2016) to plot the share of the gender pay gap that can be explained by each factor we consider: speed, experience (lifetime trips controls), where to drive (geohash controls), and when to drive (hour of week controls).

Table 9: Parameter averages by experience

\begin{tabular}{|c|c|c|c|c|c|c|}
\hline \multirow[b]{2}{*}{ Lifetime trips } & \multicolumn{3}{|c|}{ Men } & \multicolumn{3}{|c|}{ Women } \\
\hline & $0-100$ & $700-800$ & $1400-1500$ & $0-100$ & $700-800$ & $1400-1500$ \\
\hline$w$ - Wait time (min) & $\begin{array}{c}9.075 \\
(0.034)\end{array}$ & $\begin{array}{c}8.740 \\
(0.053)\end{array}$ & $\begin{array}{c}8.305 \\
(0.062)\end{array}$ & $\begin{array}{c}8.954 \\
(0.056)\end{array}$ & $\begin{array}{c}8.214 \\
(0.095)\end{array}$ & $\begin{array}{c}8.473 \\
(0.139)\end{array}$ \\
\hline$d_{0}-$ Accepts-to-pickup distance (mi) & $\begin{array}{c}0.642 \\
(0.002)\end{array}$ & $\begin{array}{c}0.535 \\
(0.003)\end{array}$ & $\begin{array}{c}0.485 \\
(0.003)\end{array}$ & $\begin{array}{c}0.591 \\
(0.003)\end{array}$ & $\begin{array}{c}0.506 \\
(0.005)\end{array}$ & $\begin{array}{c}0.471 \\
(0.006)\end{array}$ \\
\hline$d_{1}-$ Trip distance $(\mathrm{mi})$ & $\begin{array}{c}5.068 \\
(0.011)\end{array}$ & $\begin{array}{c}5.149 \\
(0.018)\end{array}$ & $\begin{array}{c}5.133 \\
(0.022)\end{array}$ & $\begin{array}{c}4.811 \\
(0.017)\end{array}$ & $\begin{array}{c}4.816 \\
(0.031)\end{array}$ & $\begin{array}{c}4.880 \\
(0.042)\end{array}$ \\
\hline$s-$ Speed $(\mathrm{mph})$ & $\begin{array}{l}20.147 \\
(0.022)\end{array}$ & $\begin{array}{l}19.798 \\
(0.034)\end{array}$ & $\begin{array}{l}19.646 \\
(0.043)\end{array}$ & $\begin{array}{l}19.056 \\
(0.034)\end{array}$ & $\begin{array}{l}18.551 \\
(0.062)\end{array}$ & $\begin{array}{l}18.703 \\
(0.083)\end{array}$ \\
\hline$S M$ - Surge multiplier & $\begin{array}{c}1.035 \\
(0.000)\end{array}$ & $\begin{array}{c}1.046 \\
(0.001)\end{array}$ & $\begin{array}{l}1.052 \\
(0.001)\end{array}$ & $\begin{array}{c}1.036 \\
(0.001)\end{array}$ & $\begin{array}{c}1.044 \\
(0.001)\end{array}$ & $\begin{array}{l}1.050 \\
(0.002)\end{array}$ \\
\hline$I-$ Per trip incentives $(\$)$ & $\begin{array}{c}0.465 \\
(0.002)\end{array}$ & $\begin{array}{c}0.847 \\
(0.004)\end{array}$ & $\begin{array}{c}0.917 \\
(0.005)\end{array}$ & $\begin{array}{c}0.523 \\
(0.004)\end{array}$ & $\begin{array}{c}0.789 \\
(0.008)\end{array}$ & $\begin{array}{c}0.877 \\
(0.011)\end{array}$ \\
\hline
\end{tabular}

Note: This table documents parameter averages from Equation 3.1 by gender and tenure. Data are limited to trips in Chicago in January-February 2017 to avoid issues with seasonality and changes in composition of driver tenure. Drivers are bucketed based on their lifetime trips before a given day. Wait time is based on time between becoming available for a dispatch (e.g., after coming online or completing a previous trip) and accepting and dispatch. Trip distance is based on actual route taken; however, accepts-to-pickup distance is the Haversine distance between corresponding coordinates. 


\section{Conclusion}

The gig economy has become an increasingly large source of earnings for millions of individuals. On Uber alone, there are over 3 million active drivers worldwide completing 15 million trips each day (Bhuiyan (2018)).

Gig economy work is often substantially differentiated from traditional jobs: individuals have more flexibility, are often paid according to a fixed contract, and retain greater control over their earnings. Despite these differences, we show that - much like with traditional jobs - there is a gender pay gap. However, unlike earlier studies, we are able to completely explain the pay gap with three main factors related to driver tastes and learning: returns to experience, a pay premium for faster driving, and preferences for where to drive. Indeed, the contribution of the return to experience to gender earnings gaps has not gotten much attention in previous empirical literature, as it is often quite difficult to measure in traditional work settings. We find that even tracking the number of weeks worked - a common proxy for experience in the literature - does not accurately quantify experience, as men work more hours per week than women and thus accumulate experience more quickly. These results suggest that the role of on-the-job learning may contribute to the gender earnings gap more broadly in the economy than previously thought.

Overall, our results suggest that, even in the gender-blind, transactional, flexible environment of the gig economy, gender-based preferences (especially the value of time not spent at paid work and, for drivers, a taste for speed) can open gender earnings gaps. The preference differences that contribute to pay differences in professional markets for lawyers and MBA's also lead to earnings gaps for drivers on Uber, suggesting they are pervasive across the skill distribution and whether in the traditional or gig workplace. 


\section{References}

Allcott, Hunt, Rebecca Diamond, and Jean-Pierre Dubé, "The Geography of Poverty and Nutrition: Food Deserts and Food Choices Across the United States," Working paper, 2017.

Altonji, Joseph G. and Rebecca M. Blank, "Race and Gender in the Labor Market," in Orley Ashenfelter and David Card, eds., Handbook of Labor Economics, Volume 3, New York: North-Holland, 1999.

Angrist, Joshua D., Sydnee Caldwell, and Jonathan V. Hall, "Uber vs. Taxi: A Driver's Eye View," 2017. NBER Working Paper \#23,891.

Azmat, Ghazala and Rosa Ferrer, "Gender Gaps in Performance: Evidence from Young Lawyers," Journal of Political Economy, October 2017, 125 (5), 1306-1355.

Babcock, Linda and Sara Laschever, Women don't ask: Negotiation and the gender divide, Princeton University Press, 2003.

Barth, Erling, Sari Pekkala Kerr, and Claudia Olivetti, "The Dynamics of Gender Earnings Differentials: Evidence from Establishment Data," 2017. NBER Working Paper 23381.

Bayard, Kimberly, Judith Hellerstein, David Neumark, and Kenneth Troske, "New Evidence on Sex Segregation and Sex Differences in Wages from Matched Employee-Employer Data," Journal of Labor Economics, 2003, 21, 887-922.

Bertrand, Marianne, "New Perspectives on Gender," in Orley Ashenfelter and David Card, eds., Handbook of Labor Economics, Volume 4b, North-Holland, Great Britain, 2011.

_, Claudia Goldin, and Lawrence F. Katz, "Dynamics of the Gender Gap for Young Professionals in the Financial and Corporate Sectors," American Economic Journal: Applied Economics, July 2010, 2 (3), 228-255.

Bhuiyan, Johana, "Uber powered four billion rides in 2017. It wants to do more â $\breve{A} \breve{T}$ and cheaper âĂ $\breve{T}$ in 2018," 2018. available at www.recode.net.

Black, Sandra E. and Philip E. Strahan, "The Division of Spoils: Rent-Sharing and Discrimination in a Regulated Industry," American Economic Review, 2001, 91, 814-831.

Blau, Francine D and Lawrence M Kahn, "The feasibility and importance of adding measures of actual experience to cross-sectional data collection," Journal of Labor Economics, 2013, 31 
(S1), S17-S58.

Blau, Francine D. and Lawrence M. Kahn, "The Gender Wage Gap: Extent, Trends, and Explanations," Journal of Economic Literature, 2017, 55, 789-865.

Buckles, Kasey S. and Daniel M. Hungerman, "Season of Birth and Later Outcomes: Old Questions, New Answers," The Review of Economics and Statistics, 2013, 95 (3), 711-724.

Card, David, Ana Rute Cardoso, and Patrick Kline, "Bargaining, Sorting, and the Gender Wage Gap: Quantifying the Impact of Firms on the Relative Pay of Women," Quarterly Journal of Economics, 2015, 131, 633-686.

Chen, M. Keith, Judith A. Chevalier, Peter E. Rossi, and Emily Oehlsen, "The Value of Flexible Work: Evidence from Uber Drivers," Working Paper 23296, National Bureau of Economic Research March 2017.

Dohmen, Thomas J., Armin Falk, David Huffman, Juergen Schupp, Uwe Sunde, and Gert G. Wagner, "Individual Risk Attitudes: Measurement, Determinants, and Behavioral Consequences," Journal of the European Economic Association, 2011, 9, 522-550.

Flory, Jeffrey A., Andreas Leibbrandt, and John A. List, "Do Competitive Workplaces Deter Female Workers? A Large-Scale Natural Field Experiment on Job Entry Decisions," The Review of Economic Studies, 2015, 82 (1), 122-155.

Gallen, Yana, "The Gender Productivity Gap," 2015. Northwestern University.

Gelbach, Jonah B., "When Do Covariates Matter? And Which Ones, and How Much?," Journal of Labor Economics, 2016, 34 (2), 509-543.

Gneezy, Uri, Muriel Niederle, and Aldo Rustichini, "Performance in Competitive Environments: Gender Differences*," The Quarterly Journal of Economics, 2003, 118 (3), 1049-1074.

Goldin, Claudia, "A grand gender convergence: Its last chapter," The American Economic Review, 2014, 104 (4), 1091-1119.

_ and Lawrence F. Katz, "A Most Egalitarian Profession: Pharmacy and the Evolution of a Family-Friendly Occupation," Journal of Labor Economics, 2016, 34, 705-746.

Gupta, Nabanita Datta and Donna S. Rothstein, "The Impact of Worker and Establishmentlevel Characteristics on Male-Female Wage Differentials: Evidence from Danish Matched 
Employee-Employer Data," Labour, 2005, 19, 1-34.

Haggag, Kareem, Brian McManus, and Giovanni Paci, "Learning by Driving: Productivity Improvements by New York City Taxi Drivers," American Economic Journal: Applied Economics, January 2017, 9 (1), 70-95.

Hirsch, Boris, Thorsten Schank, and Claus Schnabel, "Differences in Labor Supply to Monopsonistic Firms and the Gender Pay Gap: An Empirical Analysis Using Linked EmployerEmployee Data from Germany," Journal of Labor Economics, 2010, 28, 291-330.

Hyperwallet, "The Future of Gig Work is Female," 2017. available at www.hyperwallet.com.

Katz, Lawrence F. and Alan B. Krueger, "The Rise and Nature of Alternative Work Arrangements in the United States, 1995-2015," 2016. NBER Working Paper \#22,667.

Leibbrandt, Andreas and John A. List, "Do Women Avoid Salary Negotiations? Evidence from a Large-Scale Natural Field Experiment," Management Science, 2015, 61 (9), 2016-2024.

Light, Audrey and Manuelita Ureta, "Early-career work experience and gender wage differentials," Journal of labor economics, 1995, 13 (1), 121-154.

Mas, Alexandre and Amanda Pallais, "Valuing Alternative Work Arrangements," American Economic Review, 2017. forthcoming.

Massie, Dawn L., Kenneth L. Campbell, and Allan F. Williams, "Traffic Accident Involvement Rates by Driver Age and Gender," Accident Analysis and Prevention, 1995, 27, 73-87.

McKinsey Global Institute, "Independent Work: Choice, Necessity, and The Gig Economy," 2016.

Mincer, Jacob and Solomon Polachek, "Family investments in human capital: Earnings of women," Journal of political Economy, 1974, 82 (2, Part 2), S76-S108.

Oyer, Paul, "The Independent Workforce in America," 2016. Upwork White Paper.

Santamarina-Rubioa, Elena, Katherine Péreza, Marta Olabarriaa, and Ana M. Novoaa, "Gender differences in road traffic injury rate using time travelled as a measure of exposure," Accident Analysis and Prevention, 2014, 65, 1-7.

The Rideshare Guy, "Driver Earnings, Satisfaction and Demographics," 2017. available at www.therideshareguy.com. 
Zoepf, Stephen, Stella Chen, Paa Adu, and Gonzalo Pozo, "The Economics of Ride Hailing: Driver Expenses, Income and Taxes," 2017. Stanford University.

\section{Appendix}

\subsection{Differences in parameters of the earnings formula}

We can more systematically analyze how parameters of the model differ between gender and how that difference feeds into the gender pay gap through Taylor series first order approximations. More precisely, the effect of the difference in parameter $v$ on hourly earnings for men versus women can be approximated by

$$
\Delta \text { Earnings }_{v} \approx P_{v}(\overline{\mathbf{X}})\left(v_{m}-v_{f}\right)
$$

where $P_{v}(\overline{\mathbf{X}})$ is the partial derivative of Equation 3.1 with respect to parameter $v$ evaluated at the

average for each parameter, $\overline{\mathbf{X}}$, and $\left(v_{m}-v_{f}\right)$ is the gender difference in parameter $v$. We can measure this difference using a regression with the parameter of interest regressed against is Male. This allows us to control for experience, where/when, and speed in order to focus on the residual gender-specific gap, i.e. the coefficient on isMale, $\hat{\beta_{m}}$. We run the model both with and without these controls.

Table 10 presents the results of these first order approximations. Due to restrictions on the availability of certain variables, these results are based on driver-hours in Chicago between May 2016 to March 2017. Table 10 allows us to examine the levers that men pull in order to earn more money. Without controls, men benefit through each parameter in the earnings function (besides incentives). In order of effect size, men benefit from higher speed $(+\$ 0.505 / \mathrm{hr})$, higher surge multipliers $(+\$ 0.206 / \mathrm{hr})$, longer trips $(+\$ 0.190 / \mathrm{hr})$, and lower accepts-to-pickup distances $(+\$ 0.008 / \mathrm{hr})$. Men do marginally worse on per-trip incentive earnings $(-\$ 0.004 / \mathrm{hr})$ and wait times (-\$0.041/hr). This nets to an additional $\$ 0.793 / \mathrm{hr}$ for men.

As we showed above, when controlling for experience, location/time, and speed (except when endogenous) the earnings gap disappears. However, this is not because men and women now have equal inputs to the earnings function. Men still earn substantially more due to faster speeds 
$(+\$ 0.248 / \mathrm{hr})$, higher surge $(+\$ 0.075 / \mathrm{hr})$, and lower wait times $(+\$ 0.016 / \mathrm{hr})$; however, that is now negated by men earning less through higher accepts-to-pickup distance $(-\$ 0.012 / \mathrm{hr})$, shorter trips $(-\$ 0.045 / \mathrm{hr})$, and less per-trip incentives $(-\$ 0.092)$. This nets to an additional $\$ 0.191$ per hour for men; however, the gap reverses to $-\$ 0.057$ without excluding the explicit returns to speed for men. Since the effects of wait time and surge on pay offset the effects of accepts to pickup distance and trip length, suggests that there exists some gender sorting in when and where to drive within our (hour of week) and geohash controls. For example, if there is an event on at a certain time in a specific week, our hour of week controls would not account for this. However, this sorting does not contribute to gender differences in wages.

The unique granularity of our data allows us to fully decompose the determinants of gender pay gap. Beyond documenting the factors that explain the gap itself-returns to experience, location and time of week, and speed - we can also examine how these different factors affect inputs into the earnings function of an Uber driver (Equation 3.1). The earnings gap can be fully explained; however, men and women are not completing identical work even once controlling for the factors above. Instead, the differences in inputs to the earnings function cancel each other out; for example, men drive in hours with higher surge, but women earn more in the incentives that Uber offers.

\subsection{Costs of driving}

We have been using total earnings for drivers as our primary measure of earnings. But, if costs differ in a way that is correlated with gender, we could have understated or overstated the gender "net" pay gap. In some ways, that is not problematic and is consistent with other work. No studies of the gender gap account for differences in costs of working, though the costs of work vary for reasons that may well correlate with gender (such as commuting, clothing, and styling). However, given that a large capital cost is a requirement for independent drivers and that they may deduct some costs from their taxes, it may be appropriate in their case to consider earnings net of direct expenses of driving for hire.

The primary costs drivers face are fuel, maintenance, depreciation, and fines for parking or moving violations. Zoepf et al. (2017) estimate median driver's expenses are 32 cents per mile. 
Table 10: Decomposing the gap: first order approximations

\begin{tabular}{|c|c|c|c|c|c|}
\hline & \multirow[b]{2}{*}{ Average } & \multicolumn{2}{|c|}{ No controls } & \multicolumn{2}{|c|}{ Controls } \\
\hline & & $\hat{\beta_{m}}$ & $\Delta$ Earnings & $\hat{\beta_{m}}$ & $\Delta$ Earnings \\
\hline$w$ - Wait time (min) & 8.012 & 0.0395 & $\$-0.041$ & -0.016 & $\$ 0.016$ \\
\hline$d_{0}-$ Accepts-to-pickup (mi) & 0.561 & -0.003 & $\$ 0.008$ & 0.004 & $\$-0.012$ \\
\hline$d_{1}-$ Trip distance $(\mathrm{mi})$ & 5.238 & 0.190 & $\$ 0.119$ & -0.070 & $\$-0.045$ \\
\hline$s-$ Speed $(\mathrm{mph})$ & 18.860 & 0.894 & $\$ 0.505$ & 0.435 & $\$ 0.248$ \\
\hline$S M$ - Surge multiplier & 1.092 & 0.009 & $\$ 0.206$ & 0.003 & $\$ 0.075$ \\
\hline$I$ - Incentive payout $(\$)$ & 1.127 & -0.002 & $\$-0.004$ & -0.041 & $\$-0.092$ \\
\hline $\begin{array}{l}\text { Week FE } \\
\text { Geohash*hour of week } \\
\text { Experience } \\
\text { Speed }\end{array}$ & & $\mathrm{X}$ & & $\begin{array}{l}\mathrm{X} \\
\mathrm{X} \\
\mathrm{X} \\
\mathrm{X}\end{array}$ & \\
\hline
\end{tabular}

Note: This table documents the marginal effect of gender on parameters of Equation 3.1 and how that effect impacts earnings. Data are limited to driver-hours between May 2016 to March 2017 - distance-to-pickup and wait time were not always reliable in earlier data. Coefficients represent the coefficient on is Male from regressions of the form parameter $\sim$ isMale + controls. "No controls" includes only controls for the calendar week. "Controls" replicates column (2) in Table 8, with controls for calendar week, experience, location/time, and speed (except when the parameter of interest is speed).

They include insurance costs but do not include fines. We will use a conservative estimate of 25 cents per mile for costs other than insurance - Uber covers drivers' insurance costs while driving. A typical Uber driver covers about 20 miles in one hour. The driver earns approximately $\$ 18$ net of Uber's current $25 \%$ average share of driver gross earnings. As a "raw" gender gap, we use the $3.56 \%$ from column 2 of Table 5 which controls only for calendar week. Based on these numbers, men net 64 cents more per hour than women before expenses. Total average costs per hour - based on 25 cents per mile - are $\$ 5$, not including fines. Men's costs would have to be $\sim 13 \%$ higher, in terms of fuel, maintenance, depreciation, and fines to erase the gender gap.

First, we consider gasoline costs. Men and women may drive cars with different average fuel efficiency. At a high-level, this appears to be true - of all miles driven by men in the data, $6.4 \%$ of them were in a Toyota Prius compared to only $3.6 \%$ of miles driven by women. Men have, on average, more incentive to invest in more fuel efficient vehicles due to their longer driving hours. To further test this, we match drivers' vehicles to fuel economy data from the EPA. ${ }^{34}$ On average

\footnotetext{
${ }^{34}$ Fuel economy data are available at the level of the vehicle make, model, year, and trim. Drivers manually enter these fields on sign-up; there are often typos or abbreviations (e.g., "s-class" instead of the exact model). We fuzzymatch based on the Levenshtein distance between the Uber model and the EPA data's model. Results are based
} 
- weighting by miles driven on Uber - women drive cars that get 25.23 miles per gallon in the city and men drive cars that get 26.85 miles per gallon. Men are getting about $6.4 \%$ more miles per gallon on average; controlling for gasoline costs would likely increase the gender pay gap.

Another cost to consider is insurance. Though insurance is a large cost for drivers, Uber pays drivers' insurance when they are working. The costs of insurance are relevant, however, as a proxy for accidents (and the downtime that goes with them) and tickets. Men pay more than women for car insurance, though the rates converge at age 26. Accident rates per mile driven are higher for young men than young women but the difference narrows or disappears around age 25. Fatality rates remain higher for men. ${ }^{35}$ However, given the insurance rates converge, it seems that the total costs of dangerous driving are about the same by gender after age 25 . This suggests that accidents and fines should only vary by gender for drivers under 26 . In our sample of Chicago drivers, $15.8 \%$ of female drivers and $14.8 \%$ of male drivers are under 26 . So our gender gap estimates should not be affected by these costs for the vast majority of our sample.

Overall, we cannot estimate differences in costs by gender nearly as precisely as we can estimate gender differences in earnings. However, we also do not see any evidence that the gender pay differences are offset by cost differences.

\subsection{Results in other cities}

We repeat our analyses for UberX/UberPOOL drivers between January 2015 and March 2017 in Boston, Detroit, and Houston. For the duration of our sample, Uber's main ridesharing competitor Lyft did not operate in Houston, making the city of particular interest.

Tables 11 through 13 present results for four specifications in each city: (1) baseline, (2) adding controls for location and time of week, (3) adding controls for experience, and (4) adding controls for speed. The results for each city tell a similar story: there is a small 3-5\% baseline gender pay gap in each city, which can be explained by differences in where/when drivers work, different levels of experience, and preferences for driving speed. In the case of Houston, the pay gap actually

only on matches with a Levenstein distance over 0.7 (about $70 \%$ of the data). Results are qualitatively similar for different Levenshtein distance thresholds.

${ }^{35}$ See Massie et al. (1995) and Santamarina-Rubioa et al. (2014). 
reverses once controlling for those three factors and men make an estimated $1.4 \%$ less per hour than women.

Table 11: Gender pay gap: Boston

\begin{tabular}{|c|c|c|c|c|}
\hline & (1) & $(2)$ & $(3)$ & (4) \\
\hline isMale & $\begin{array}{l}0.0493 \\
(0.004)\end{array}$ & $\begin{array}{l}0.0305 \\
(0.003)\end{array}$ & $\begin{array}{l}0.0090 \\
(0.003)\end{array}$ & $\begin{array}{c}-0.0020 \\
(0.003)\end{array}$ \\
\hline Trips completed: $100-500$ & & & $\begin{array}{l}0.0742 \\
(0.002)\end{array}$ & $\begin{array}{l}0.0805 \\
(0.002)\end{array}$ \\
\hline Trips completed: $500-1000$ & & & $\begin{array}{l}0.0933 \\
(0.002)\end{array}$ & $\begin{array}{l}0.0978 \\
(0.002)\end{array}$ \\
\hline Trips completed: $1000-2500$ & & & $\begin{array}{l}0.1107 \\
(0.002)\end{array}$ & $\begin{array}{l}0.1135 \\
(0.002)\end{array}$ \\
\hline Trips completed: >2500 & & & $\begin{array}{l}0.1361 \\
(0.003)\end{array}$ & $\begin{array}{l}0.1378 \\
(0.003)\end{array}$ \\
\hline logSpeed & & & & $\begin{array}{l}0.4303 \\
(0.001)\end{array}$ \\
\hline Intercept & $\begin{array}{l}3.2016 \\
(0.004)\end{array}$ & $\begin{array}{l}3.2198 \\
(0.003)\end{array}$ & $\begin{array}{l}3.1432 \\
(0.003)\end{array}$ & $\begin{array}{l}1.9150 \\
(0.005)\end{array}$ \\
\hline Week & $\mathrm{X}$ & $\mathrm{X}$ & $\mathrm{X}$ & $\mathrm{X}$ \\
\hline Geohash*hour of week & & $\mathrm{X}$ & $\mathrm{X}$ & $\mathrm{X}$ \\
\hline $\begin{array}{l}\mathrm{N} \\
R^{2}\end{array}$ & $\begin{array}{c}13,912,058 \\
0.048\end{array}$ & $\begin{array}{c}13,912,058 \\
0.200\end{array}$ & $\begin{array}{c}13,912,058 \\
0.207\end{array}$ & $\begin{array}{c}13,912,058 \\
0.305\end{array}$ \\
\hline
\end{tabular}

Note: Data include all driver-hours for a random sample of $40 \%$ of UberX/Pool drivers in Boston, January 2015 to March 2017. Data are sampled to make the computations more tractable. Geohash*hour of week indicates controls for geohash, hour of week, and the interaction between the two. Tenure is measured as lifetime trips completed before a given day of work. Speed is measured as trip distance divided by trip duration in a given driver-hour. Standard errors (clustered at the driver-level) in parentheses.

\subsection{Differential returns to learning}

To test whether men and women learn at different rates, we include an interaction for driver gender in our regressions estimating the returns to experience. As shown in Table 14, there is no evidence of differential learning.

\subsection{Returns to experience}

The returns to experience we document could be driven by selection bias - for example, perhaps drivers with lower earnings drop off the platform and those that reach the higher tenure bins had 
Table 12: Gender pay gap: Detroit

\begin{tabular}{|c|c|c|c|c|}
\hline & (1) & $(2)$ & $(3)$ & $(4)$ \\
\hline isMale & $\begin{array}{l}0.0361 \\
(0.003)\end{array}$ & $\begin{array}{l}0.0164 \\
(0.002)\end{array}$ & $\begin{array}{l}0.0102 \\
(0.003)\end{array}$ & $\begin{array}{l}0.0010 \\
(0.003)\end{array}$ \\
\hline Trips completed: $100-500$ & & & $\begin{array}{l}0.0323 \\
(0.002)\end{array}$ & $\begin{array}{l}0.0196 \\
(0.002)\end{array}$ \\
\hline Trips completed: $500-1000$ & & & $\begin{array}{l}0.0471 \\
(0.003)\end{array}$ & $\begin{array}{l}0.0300 \\
(0.003)\end{array}$ \\
\hline Trips completed: $1000-2500$ & & & $\begin{array}{l}0.0576 \\
(0.004)\end{array}$ & $\begin{array}{l}0.0379 \\
(0.003)\end{array}$ \\
\hline Trips completed: $>2500$ & & & $\begin{array}{l}0.0719 \\
(0.006)\end{array}$ & $\begin{array}{l}0.0499 \\
(0.006)\end{array}$ \\
\hline $\operatorname{logSpeed}$ & & & & $\begin{array}{l}0.6082 \\
(0.001)\end{array}$ \\
\hline Intercept & $\begin{array}{l}2.8938 \\
(0.004)\end{array}$ & $\begin{array}{l}2.9106 \\
(0.003)\end{array}$ & $\begin{array}{l}2.8833 \\
(0.002)\end{array}$ & $\begin{array}{l}0.8608 \\
(0.005)\end{array}$ \\
\hline Week & $\mathrm{X}$ & $\mathrm{X}$ & $\mathrm{X}$ & $\mathrm{X}$ \\
\hline Geohash*hour of week & & $\mathrm{X}$ & $\mathrm{X}$ & $\mathrm{X}$ \\
\hline $\begin{array}{l}\mathrm{N} \\
R^{2}\end{array}$ & $\begin{array}{c}3,807,809 \\
0.038\end{array}$ & $\begin{array}{c}3,807,809 \\
0.142\end{array}$ & $\begin{array}{c}3,807,809 \\
0.143\end{array}$ & $\begin{array}{c}3,807,809 \\
0.344\end{array}$ \\
\hline
\end{tabular}

Note: Data include all driver-hours for UberX/Pool drivers in Houston, January 2015 to March 2017. Geohash*hour of week indicates controls for geohash, hour of week, and the interaction between the two. Tenure is measured as lifetime trips completed before a given day of work. Speed is measured as trip distance divided by trip duration in a given driver-hour. Standard errors (clustered at the driver-level) in parentheses. 
Table 13: Gender pay gap: Houston

\begin{tabular}{|c|c|c|c|c|}
\hline & (1) & $(2)$ & $(3)$ & $(4)$ \\
\hline isMale & $\begin{array}{l}0.0327 \\
(0.004)\end{array}$ & $\begin{array}{l}0.0154 \\
(0.003)\end{array}$ & $\begin{array}{l}0.0027 \\
(0.003)\end{array}$ & $\begin{array}{c}-0.0142 \\
(0.002)\end{array}$ \\
\hline Trips completed: $100-500$ & & & $\begin{array}{l}0.0450 \\
(0.001)\end{array}$ & $\begin{array}{l}0.0237 \\
(0.001)\end{array}$ \\
\hline Trips completed: $500-1000$ & & & $\begin{array}{l}0.0675 \\
(0.002)\end{array}$ & $\begin{array}{l}0.0302 \\
(0.002)\end{array}$ \\
\hline Trips completed: 1000-2500 & & & $\begin{array}{l}0.0834 \\
(0.002)\end{array}$ & $\begin{array}{l}0.0344 \\
(0.002)\end{array}$ \\
\hline Trips completed: $>2500$ & & & $\begin{array}{l}0.0919 \\
(0.003)\end{array}$ & $\begin{array}{l}0.0288 \\
(0.003)\end{array}$ \\
\hline logSpeed & & & & $\begin{array}{l}0.7492 \\
(0.001)\end{array}$ \\
\hline Intercept & $\begin{array}{l}2.8728 \\
(0.004)\end{array}$ & $\begin{array}{l}2.8877 \\
(0.003)\end{array}$ & $\begin{array}{l}2.8441 \\
(0.003)\end{array}$ & $\begin{array}{l}0.4107 \\
(0.005)\end{array}$ \\
\hline Week & $\mathrm{X}$ & $\mathrm{X}$ & $\mathrm{X}$ & $\mathrm{X}$ \\
\hline Geohash*hour of week & & $\mathrm{X}$ & $\mathrm{X}$ & $\mathrm{X}$ \\
\hline $\begin{array}{l}\mathrm{N} \\
R^{2}\end{array}$ & $\begin{array}{c}6,770,183 \\
0.021\end{array}$ & $\begin{array}{c}6,770,183 \\
0.112\end{array}$ & $\begin{array}{c}6,770,183 \\
0.114\end{array}$ & $\begin{array}{c}6,770,183 \\
0.368\end{array}$ \\
\hline
\end{tabular}

Note: Data include all driver-hours for all UberX/Pool drivers in Detroit, January 2015 to March 2017. Geohash*hour of week indicates controls for geohash, hour of week, and the interaction between the two. Tenure is measured as lifetime trips completed before a given day of work. Speed is measured as trip distance divided by trip duration in a given driverhour. Standard errors (clustered at the driver-level) in parentheses. 
Table 14: Differential learning

\begin{tabular}{|c|c|c|}
\hline & $(1)$ & $(2)$ \\
\hline isMale & $\begin{array}{l}0.0145 \\
(0.002)\end{array}$ & $\begin{array}{l}0.0096 \\
(0.002)\end{array}$ \\
\hline Trips completed: $100-500$ & $\begin{array}{l}0.0529 \\
(0.003)\end{array}$ & $\begin{array}{l}0.0343 \\
(0.002)\end{array}$ \\
\hline Trips completed: $500-1000$ & $\begin{array}{l}0.0768 \\
(0.004)\end{array}$ & $\begin{array}{l}0.0493 \\
(0.003)\end{array}$ \\
\hline Trips completed: $1000-2500$ & $\begin{array}{l}0.0995 \\
(0.006)\end{array}$ & $\begin{array}{l}0.0655 \\
(0.004)\end{array}$ \\
\hline Trips completed: $>2500$ & $\begin{array}{l}0.1453 \\
(0.014)\end{array}$ & $\begin{array}{l}0.0919 \\
(0.009)\end{array}$ \\
\hline isMale*Trips completed: $100-500$ & $\begin{array}{c}-0.0004 \\
(0.003)\end{array}$ & $\begin{array}{c}-0.0006 \\
(0.003)\end{array}$ \\
\hline isMale*Trips completed: $500-1000$ & $\begin{array}{l}0.0004 \\
(0.004)\end{array}$ & $\begin{array}{c}-0.0002 \\
(0.004)\end{array}$ \\
\hline isMale*Trips completed: $1000-2500$ & $\begin{array}{l}0.0006 \\
(0.006)\end{array}$ & $\begin{array}{c}-0.0022 \\
(0.006)\end{array}$ \\
\hline isMale*Trips completed: $>2500$ & $\begin{array}{c}-0.0069 \\
(0.0012)\end{array}$ & $\begin{array}{c}-0.0067 \\
(0.012)\end{array}$ \\
\hline Intercept & $\begin{array}{l}3.0223 \\
(0.002)\end{array}$ & $\begin{array}{l}3.0571 \\
(0.002)\end{array}$ \\
\hline Week & $\mathrm{X}$ & $\mathrm{X}$ \\
\hline Geohash*hour of week & & $\mathrm{X}$ \\
\hline $\begin{array}{l}\mathrm{N} \\
R^{2}\end{array}$ & $\begin{array}{c}11,572,163 \\
0.047\end{array}$ & $\begin{array}{c}11,572,163 \\
0.164\end{array}$ \\
\hline
\end{tabular}

Note: The table expands on results presented in Table 6 by adding interacting gender and experience. Outcome variable is log of hourly earnings. Standard errors (clustered at the driver-level) in parentheses. 
always been earning more per hour. To test this, we add driver fixed effects to our model. Results are presented in table 15. Adding driver fixed effects attenuates the learning curve by about $~ 30 \%$ with time and location controls and $\sim 35 \%$ with only controls for the calendar week.

There are other forms of selection bias that could affect how we measure the returns to experience. For example, perhaps drivers construct an expectation of future earnings growth and drop off the platform if the do not expect to continue learning.

Table 15: Returns to experience, driver fixed effects

\begin{tabular}{|c|c|c|c|c|}
\hline & (1) & $(2)$ & $(3)$ & $(4)$ \\
\hline Trips completed: $100-500$ & $\begin{array}{l}0.0539 \\
(0.001)\end{array}$ & $\begin{array}{l}0.0349 \\
(0.001)\end{array}$ & $\begin{array}{l}0.0344 \\
(0.001)\end{array}$ & $\begin{array}{l}0.0242 \\
(0.001)\end{array}$ \\
\hline Trips completed: 500-1000 & $\begin{array}{l}0.0788 \\
(0.002)\end{array}$ & $\begin{array}{l}0.0527 \\
(0.002)\end{array}$ & $\begin{array}{l}0.0503 \\
(0.002)\end{array}$ & $\begin{array}{l}0.0374 \\
(0.002)\end{array}$ \\
\hline Trips completed: $1000-2500$ & $\begin{array}{l}0.1023 \\
(0.002)\end{array}$ & $\begin{array}{l}0.0688 \\
(0.002)\end{array}$ & $\begin{array}{l}0.0650 \\
(0.002)\end{array}$ & $\begin{array}{l}0.0495 \\
(0.002)\end{array}$ \\
\hline Trips completed: $>2500$ & $\begin{array}{l}0.1421 \\
(0.004)\end{array}$ & $\begin{array}{l}0.0925 \\
(0.003)\end{array}$ & $\begin{array}{l}0.0876 \\
(0.003)\end{array}$ & $\begin{array}{l}0.0668 \\
(0.003)\end{array}$ \\
\hline Intercept & $\begin{array}{l}3.0326 \\
(0.001)\end{array}$ & $\begin{array}{l}3.0614 \\
(0.002)\end{array}$ & $\begin{array}{l}3.0640 \\
(0.001)\end{array}$ & $\begin{array}{l}3.0771 \\
(0.002)\end{array}$ \\
\hline Week & $\mathrm{X}$ & $\mathrm{X}$ & $\mathrm{X}$ & $\mathrm{X}$ \\
\hline Geohash*hour of week & & & & $\mathrm{X}$ \\
\hline Driver & & $\mathrm{X}$ & & $\mathrm{X}$ \\
\hline $\mathrm{N}$ & $11,572,163$ & $11,572,163$ & $11,572,163$ & $11,572,163$ \\
\hline$R^{2}$ & 0.048 & 0.123 & 0.165 & 0.205 \\
\hline
\end{tabular}

\subsection{Driving speed}

We model driving speed against gender to test whether men drive faster after controlling for experience, location, and hour of week. Results presented in Table 16 show that men drive $2.2 \%$ faster after controls. Table 17 presents similar results based on data from the National Household Travel Survey; even in contexts where there is no pecuniary incentive to drive faster, men still do so.

\subsection{Additional graphs \& tables}


Table 16: Effect of gender on driving speed

\begin{tabular}{|c|c|c|}
\hline & (1) & $(2)$ \\
\hline isMale & $\begin{array}{l}0.0236 \\
(0.002)\end{array}$ & $\begin{array}{l}0.0218 \\
(0.002)\end{array}$ \\
\hline Trips completed: $100-500$ & & $\begin{array}{l}0.0039 \\
(0.001)\end{array}$ \\
\hline Trips completed: $500-1000$ & & $\begin{array}{l}0.0075 \\
(0.001)\end{array}$ \\
\hline Trips completed: 1000-2500 & & $\begin{array}{l}0.0096 \\
(0.002)\end{array}$ \\
\hline Trips completed: $>2500$ & & $\begin{array}{l}0.0110 \\
(0.002)\end{array}$ \\
\hline Intercept & $\begin{array}{l}2.9174 \\
(0.001)\end{array}$ & $\begin{array}{l}2.9119 \\
(0.001)\end{array}$ \\
\hline Week & $\mathrm{X}$ & $\mathrm{X}$ \\
\hline Geohash*hour of week & $\mathrm{X}$ & $\mathrm{X}$ \\
\hline $\begin{array}{l}\mathrm{N} \\
R^{2}\end{array}$ & $\begin{array}{c}11,572,163 \\
0.352\end{array}$ & $\begin{array}{c}11,572,163 \\
0.352\end{array}$ \\
\hline
\end{tabular}

Note: This table regresses log speed in a given driver-hour against the driver's gender and experience. Speed is measured as distance traveled on-trip in an hour over duration on-trip. Standard errors (clustered at the driver-level) in parentheses.

Table 17: Effect of gender on driving speed: NHTS data

\begin{tabular}{lcccc}
\hline & $(1)$ & $(2)$ & $(3)$ & $(4)$ \\
\hline Male & 0.0881 & 0.113 & 0.0494 & 0.0772 \\
& $(0.005)$ & $(0.038)$ & $(0.005)$ & $(0.016)$ \\
Intercept & 2.973 & 2.810 & 3.197 & 3.103 \\
& $(0.004)$ & $(0.024)$ & $(0.068)$ & $(0.125)$ \\
\hline $\mathrm{N}$ & 656,904 & 3,677 & 656,904 & 0.582 \\
$R^{2}$ & 0.004 & 0.007 & 0.124 & $\mathrm{X}$ \\
Nationwide Sample & $\mathrm{X}$ & $\mathrm{X}$ & $\mathrm{X}$ & $\mathrm{X}$ \\
Chicagoland Sample & & & $\mathrm{X}$ & $\mathrm{X}$ \\
Controls & & & & \\
Vehicle FE & & & & \\
\hline
\end{tabular}

Note: The table presents estimates the gender gap in log driving speed using data from the National Household Travel Survey. Dependent variable is average miles per hour driven on a single trip. Column 3 includes controls for household income bins, driver education bins, dummies for why the trip was taken, dummies for why the previous trip was taken, day of the week, hour of day, age dummies, MSA size bins, and whether the interstate was used on trip. Column 4 add individual vehicle fixed effects. Since each household only record trips on a single day, Column 4 only compares male and female speeds driven in the same vehicle on the same day. Standard errors in parentheses. 
Figure 6: Distribution of hours of the week worked by gender

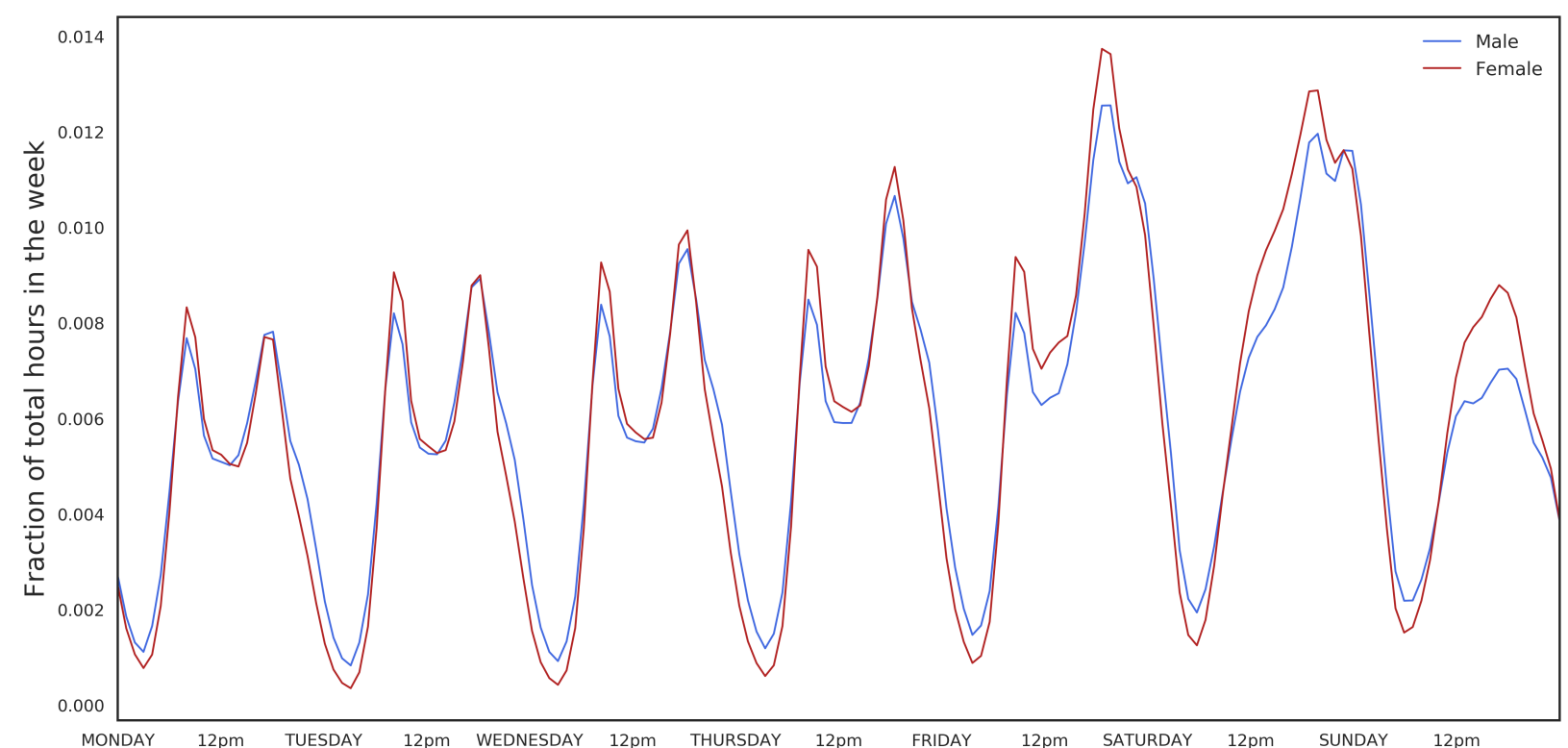

Note: This figure shows which hours of the week men and women work; each point represents the fraction of their total hours in the week that men (or women) spend working in that specific hour of the week. Data are limited to Chicago UberX/UberPOOL drivers in Chicago, January 2015-March 2017.

Figure 7: Average earnings over course of week

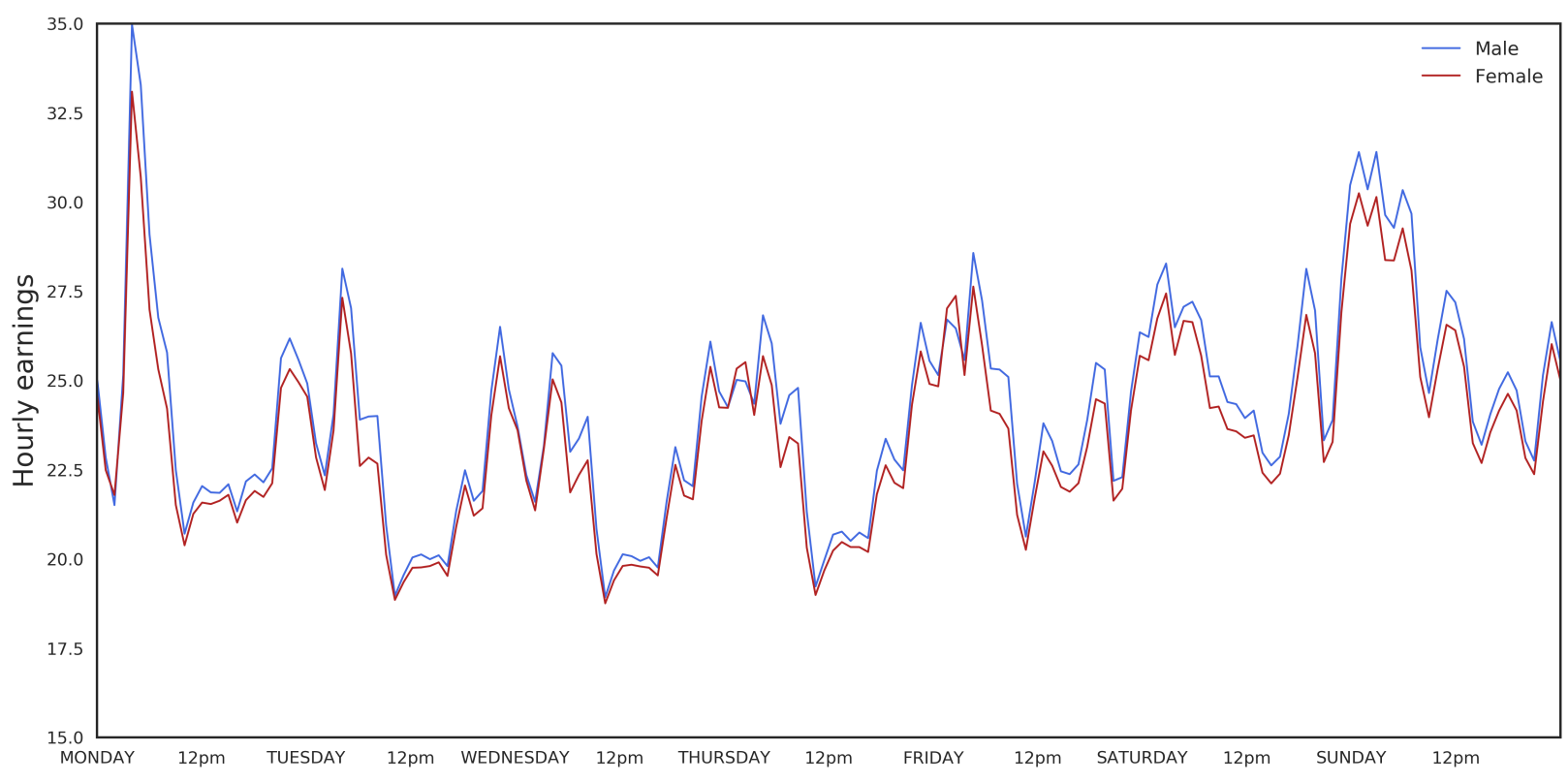

Note: This figure graphs the average earnings by gender for different hours of the week. Data are limited to Chicago UberX/UberPOOL drivers in Chicago, January 2015-March 2017. Earnings include both incentive and organic earnings. 